\title{
SOEP
}

SOEPpapers

on Multidisciplinary Panel Data Research

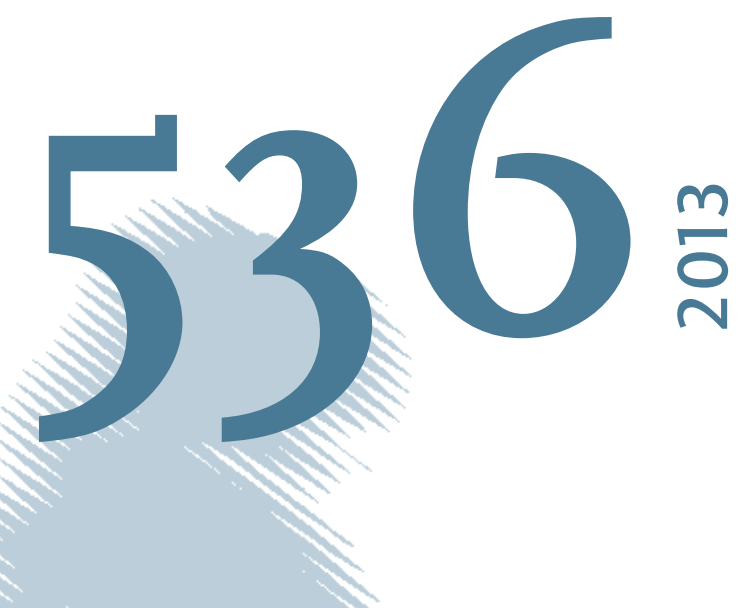

\section{Early Child Care and Child Development: For Whom it Works and Why}

Christina Felfe and Rafael Lalive 


\section{SOEPpapers on Multidisciplinary Panel Data Research}

at DIW Berlin

This series presents research findings based either directly on data from the German SocioEconomic Panel Study (SOEP) or using SOEP data as part of an internationally comparable data set (e.g. CNEF, ECHP, LIS, LWS, CHER/PACO). SOEP is a truly multidisciplinary household panel study covering a wide range of social and behavioral sciences: economics, sociology, psychology, survey methodology, econometrics and applied statistics, educational science, political science, public health, behavioral genetics, demography, geography, and sport science.

The decision to publish a submission in SOEPpapers is made by a board of editors chosen by the DIW Berlin to represent the wide range of disciplines covered by SOEP. There is no external referee process and papers are either accepted or rejected without revision. Papers appear in this series as works in progress and may also appear elsewhere. They often represent preliminary studies and are circulated to encourage discussion. Citation of such a paper should account for its provisional character. A revised version may be requested from the author directly.

Any opinions expressed in this series are those of the author(s) and not those of DIW Berlin. Research disseminated by DIW Berlin may include views on public policy issues, but the institute itself takes no institutional policy positions.

The SOEPpapers are available at

http://www.diw.de/soeppapers

\section{Editors:}

Jürgen Schupp (Sociology, Vice Dean DIW Graduate Center)

Gert G. Wagner (Social Sciences)

Conchita D'Ambrosio (Public Economics)

Denis Gerstorf (Psychology, DIW Research Director)

Elke Holst (Gender Studies, DIW Research Director)

Frauke Kreuter (Survey Methodology, DIW Research Professor)

Martin Kroh (Political Science and Survey Methodology)

Frieder R. Lang (Psychology, DIW Research Professor)

Henning Lohmann (Sociology, DIW Research Professor)

Jörg-Peter Schräpler (Survey Methodology, DIW Research Professor)

Thomas Siedler (Empirical Economics)

C. Katharina Spieß (Empirical Economics and Educational Science)

ISSN: 1864-6689 (online)

German Socio-Economic Panel Study (SOEP)

DIW Berlin

Mohrenstrasse 58

10117 Berlin, Germany

Contact: Uta Rahmann | soeppapers@diw.de 


\title{
Early Child Care and Child Development: For Whom it Works and Why
}

\author{
Christina Felfe, University of St. Gallen and CESifo* \\ Rafael Lalive, University of Lausanne, CEPR, CESifo and IZA ${ }^{\dagger}$ \\ First version: October 2009 \\ This version: December 2012
}

\begin{abstract}
Many countries are currently expanding access to child care for young children. But are all children equally likely to benefit from such expansions? We address this question by adopting a marginal treatment effects framework. We study the West German setting where high quality center-based care is severely rationed and use within state differences in child care supply as exogenous variation in child care attendance. Data from the German Socio-Economic Panel provides comprehensive information on child development measures along with detailed information on child care, mother-child interactions, and maternal labor supply. Results indicate strong differences in the effects of child care with respect to observed characteristics (children's age, birth weight and socio-economic background), but less so with respect to unobserved determinants of selection into child care. Underlying mechanisms are a substitution of maternal care with center-based care, an increase in average quality of maternal care, and an increase in maternal earnings.
\end{abstract}

JEL Classification: J13, I21, I38

Keywords: child care, child development, marginal treatment effects

${ }^{*}$ We appreciate comments and suggestions by Josh Angrist, Jo Blanden, Amy Challen, Bernd Fitzenberger, Eric French, Maria Fitzpatrick, Marco Francesconi, Tarjei Havnes, Michael Lechner, Steven Lehrer, Alan Manning, Blaise Melly, Björn Öckert, Hessel Oosterbeek, Steve Pischke, Kjell Salvanes, Analía Schlosser, Chris Taber, Emma Tominey, and seminar participants at Albert-Ludwig University, Norwegian School of Economics and Business Administration, CEP London, CESIfo Munich, DIW Berlin, University Pompeu Fabra, University of Lausanne, University of St. Gallen and SOLE, 2011. Rafael Lalive acknowledges financial support from NCCR LIVES. Christina Felfe thanks the German Institute for Economic Research (DIW) for their hospitality and Jan Göbel for his data support. Address: Christina Felfe, Varnbüelstrasse 14 CH-9000 St. Gallen, Christina.Felfe@unisg.ch.

${ }^{\dagger}$ Address: Rafael Lalive, Department of Economics, University of Lausanne, CH-1015 Lausanne-Dorigny, Rafael.Lalive@unil.ch. 


\section{Introduction}

What role does center-based care play in the process of children's skill acquisition early in life? Investigating this question is important for several reasons. First, policies aiming to encourage female labor force participation via expanding the supply of institutionalized care need to take the potential effects on child development into account. Second, providing evidence on the specific role of alternative care modes is relevant for a better understanding of the process of skill acquisition early in life. Third, understanding the effects of child care is important because early life conditions have long lasting effects on the formation of cognitive and non-cognitive skills (Heckman and Masterov, 2007).

The focus of this study lies on the impact of shifting hours of care from mothers to centerbased care on children's short-run skill development (at age 2-3 years old). Center-based care may affect children's development for at least three reasons. First, a child spends less time with her or his own mother, but more time in the child care center. Second, center-based care may affect the average quality of care provided by the mother if the hours spent in care substitute for hours of low quality maternal care. Third, child care frees up time for market work and hence might increase family income. Effects on children's development due to increased family income may cause rather positive effects (see, for instance, Dahl and Lochner, 2012, Gonzalez, 2012, or Black et al., 2012). In contrast, child care may help or hinder child development depending on whether the quality of center-based care is better or worse than the quality of care provided by the mother. In addition, if selection into center-based care is systematically correlated with the quality of maternal care, the returns for the average child enrolled in center-based care are not the same as the returns for children attending center-based care once it gets expanded.

In this paper, we are particularly interested in understanding who selects into center-based care and how the effects vary depending on observable and unobservable determinants of selection into center-based care. To address these questions, we employ a marginal treatment effects framework (MTE). Doing so allows us to not only model effect heterogeneity with respect to observable characteristics, but also to estimate the returns to center-based care at different margins of the unobserved component of the propensity to attend a child care center. In addition, the MTE framework allows us to derive the marginal returns to different policies inducing an expansion in center-based care attendance (see Carneiro et al., 2011, for a recent discussion).

The focus of our study lies on the child care system in West Germany, a setting with very low levels of center-based care (in 1990, slots were available for 1.8 out of 100 children age 03 years old, in 2002 for 2.8 out of 100 children). Striking differences between West and East Germany (where in 1990 the coverage rate amounted to $54.2 \%$ ) and apparent supply constraints initiated a major expansion in center-based care. Yet, timing and intensity of the expansion varied dramatically not only across, but also within states, leading to very different levels of 
supply across counties and birth cohorts.

Our empirical analysis is based on the mother-child questionnaire of the German Socioeconomic Panel (SOEP). Starting with the birth cohort 2002, the SOEP interviews mothers regarding the development of their children at age 0-1 years and age 2-3 years. The questionnaire contains a battery of questions based on the Vineland Adaptive Behaviors Scale concerning language, social, daily, and motor skills (Sparrow and Cicchetti, 1985). It also provides information that allows us to assess the role of three key mechanisms: hours spent in different care modes, quality of care provided by the mother, and maternal labor supply. We merge county level information on available center-based care and on a variety of socioeconomic features of the county where the family resided at child birth to the SOEP data.

Our identification strategy relies on county level differences in the availability of centerbased child care. Parents have a larger chance of securing a slot for their children in counties that offer many slots in center-based care than in counties that offer few slots. Thus, county level supply of center-based child care is related to individual attendance in a situation of excess demand - the situation of West Germany in the period we analyze. In our analysis we condition on a range of key predictors of county level demand for child care: fertility, female employment, unemployment, GDP per capita, migration, and the degree of urbanicity. As a result, only the within state component of child care supply that cannot be predicted by these key determinants of child care demand serve for identification. This remaining variation in child care supply is arguably exogenous to child development. Regional child care provision is a lengthy administrative process. Authorities at the county level project first the demand for child care in their region, then non-profit organizations submit their intentions to open child care centers, and finally authorities at the state level must approve the applications for new child care centers. This suggests that the actual number of slots available to any given birth cohort is never identical to child care demand, but differs due to planning errors, no approval, delays in construction or constrained availability of pedagogical staff. We support the key identifying assumption with two pieces of empirical evidence. First, individual attendance is unrelated to county level variables once we account for child care supply. In the framework of Altonji et al. (2005), this means that bias due to unobserved regional determinants of child development is unlikely. Second, child care supply is conditionally orthogonal to a range of key determinants of child development (birth outcomes, proxies for parenting style and mother preferences).

Our results indicate, first, that children of high-educated and high-income families are first to be registered in child care - hence there is selection into child care that favors children from advantaged socio-economic backgrounds. Second, there is considerable heterogeneity in returns to child care with respect to observable characteristics of children, but less so with respect to unobserved determinants of the propensity to attend child care. Returns to attending child care are higher for boys, younger children, with low birth weight and from lower socio- 
economic backgrounds. As a result, drawing conclusions about the consequences of expanding child care based on the estimated returns for children currently attending child care would lead to erroneous policy recommendations. And indeed, child care is more beneficial for children who enter child care once it gets expanded than for children who are currently enrolled. Third, underlying mechanisms are a crowding out of time spent mostly with the mother, a reduction in the frequency with which mothers engage in low quality activities with their children (e.g. running errands or watching TV) and a simultaneous increase the frequency of high quality activities (e.g. reading, singing or painting). Maternal labor supply increases and so does the mother's gross income. While the increase in net household income is not sufficiently large to be detected by our estimates, we can not rule out an increase in household income as a possible explanation for improved child development.

The question of how child development is related to child care has been discussed by two main strands of the literature. ${ }^{1}$ The first strand of literature investigates the effect of universally accessible child care on children's skill acquisition. There is a large body of research on the effects of non-parental care during pre-school ages (e.g. Berlinski et al., 2009, Cascio, 2009, Dustmann et al., 2012, Felfe et al., 2012, Fitzpatrick, 2008, Gormley Jr. et al., 2008, Havnes and Mogstad, 2011, Magnuson et al., 2007). In contrast to this, the body of research on the effects of nonparental care during early ages (0-3 years) is fairly small. ${ }^{2}$ Focusing on the Canadian province of Quebec, Baker et al. (2008) find that lowering the out-of-pocket cost of public child care increases its usage, but also crowds out existing private care arrangements. While stimulating maternal employment, the child care subsidy led to more hostile parenting styles and thus to a deterioration of child well-being. Datta-Gupta and Simonsen (2010) concentrate on the effect of exposure to different types of child care in Denmark and find that children benefit more from center-based care than from low quality day care. Using regional variation in the availability of child care in Chile, Noboa Hidalgo and Urzúa (2010) find short-run gains from child care targeted to children aged 5-14 months, particularly in motor and cognitive skills.

The second strand focuses on understanding the consequences of maternal employment on children's achievement. While some of these studies show that maternal employment may improve intellectual performance through increasing household incomes (Blau and Grossberg, 1992), others have shown that it leads to a deterioration of children's cognitive outcomes (Baum, 2003; James-Burdumy, 2005). Still others suggest that the effects may depend on the characteristics of mothers and families (see Ruhm, 2004, and Brooks-Gunn et al., 2002, for an overview).

\footnotetext{
${ }^{1} \mathrm{~A}$ further related strand focuses on the effects of pre-school interventions targeted at disadvantaged children. These targeted interventions have demonstrated strong beneficial impacts on the development of participating children. For an overview please refer to Blau and Currie (2006) or Heckman and Masterov (2007).

${ }^{2}$ There is some earlier literature in the child development field providing descriptive evidence on the relation between non-parental child care during early childhood and children's skills (e.g. Belsky et al., 2007 or Belsky, 2001).
} 
Yet, several recent studies, evaluating the effect of expanding parental leave on children's longrun development, do not find any significant effect (Wuertz-Rasmussen, 2010, Baker and Milligan, 2012, Dustmann and Schoenberg, 2012), with the exception of Carneiro et al. (2010), who detect some positive effects on educational and labor market outcomes at age 25 in Norway.

This paper adds to the existing literature in the following aspects. First, we discuss heterogeneity in the effects of center-based care depending on observed background characteristics as well as on unobserved determinants of entry. Doing so is important because it highlights strong differences in the effects of early care with respect to observed characteristics. This information is central for policy since it singles out the populations whose children will benefit more (or less) from center-based care. Second, to our knowledge, this paper is one of the first to provide detailed evidence on the mechanisms underlying the effects of early child care on child development. This information further enhances our understanding of differential impacts of early child care and of children's human capital production.

The remainder of this paper is structured as follows. Section 2 discusses the institutional background. Section 3 provides information on the data and a set of key descriptive statistics. Section 4 introduces the econometric framework and identification strategy. Section 5 presents the main results, and section 6 provides a summary and implications of our findings.

\section{Institutional Background}

Child care supply has been traditionally rather scarce in West Germany. ${ }^{3}$ Politicians have until recently embraced the view that child care is the responsibility of each family and that mothers should best care for their children until they enter Kindergarten (starting at age 3). In support of this view, West Germany rapidly expanded parental leave from 3 months in 1979 to 36 months of job-protected, and 24 months of paid leave in 1992. Yet, the supply of formal child care for children 0-3 years old remained very limited.

Only after German Unification in 1990, when striking differences between the child care system in West and East Germany became apparent, a public discussion about the relevance of universal child care arose. In 1996, the German government enacted the "Kinder- und Jugendhilfe Gesetz" (child and adolescent support law), which entitled a child from age 3 on to a legal claim for a slot in Kindergarten. As a consequence, by 2002 children at Kindergarten age were fully covered across all West German states. Child care for younger children remained, however, at very low levels. In 2002 (the earliest birth cohort in our sample), available slots covered only a minor fraction of all children age 0-3 (see Table 1). In basically all West German states, children faced a supply of $2-5 \%$. Only in the city states, Bremen and Hamburg, coverage

\footnotetext{
${ }^{3}$ All facts about the institutional background are taken from Dittrich et al. (2002), Riedel et al. (2005) and Huesken (2010).
} 
Table 1: Supply of slots per child across and within West German states

\begin{tabular}{lcccccccc}
\hline \hline & \multicolumn{3}{c}{2002} & & & \multicolumn{3}{c}{2008} \\
& Average & Lowest & Highest & & Average & Lowest & Highest \\
\cline { 2 - 4 } \cline { 6 - 7 } Baden Wuerttemberg & 0.02 & 0.00 & 0.12 & & 0.12 & 0.06 & 0.30 \\
Bavaria & 0.02 & 0.00 & 0.09 & & 0.12 & 0.04 & 0.25 \\
Bremen & 0.10 & 0.05 & 0.11 & & 0.12 & 0.06 & 0.12 \\
Hamburg & 0.13 & 0.13 & 0.13 & & 0.18 & 0.18 & 0.18 \\
Hesse & 0.04 & 0.00 & 0.11 & & 0.12 & 0.08 & 0.18 \\
Lower Saxony & 0.02 & 0.00 & 0.09 & & 0.08 & 0.03 & 0.17 \\
North-Rhine Westphalia & 0.02 & 0.00 & 0.06 & & 0.07 & 0.03 & 0.14 \\
Rhineland-Palatinate & 0.03 & 0.00 & 0.08 & & 0.14 & 0.07 & 0.24 \\
Saarland & 0.05 & 0.03 & 0.07 & & 0.13 & 0.11 & 0.19 \\
Schleswig Holstein & 0.03 & 0.00 & 0.05 & & 0.07 & 0.05 & 0.11 \\
\hline \hline
\end{tabular}

Notes: Slots are reported as number of slots per 100 children age 0-3 years old.

Source: Kinder- und Jugendhilfe Statistik, Own Calculations.

was substantially higher (10 and $13 \%$, respectively). Yet, supply varied substantially within states, with some counties reaching the level of child care available in the city states. In Baden Wuerttemberg, for instance, supply ranged from 0 to $12 \%$.

In 2005, the German government enacted the "Tagesbetreuungsausbau Gesetz" (day care expansion law), a law which postulated an expansion of child care for children age 0-3 while respecting quality standards. The explicit goal of this law was to increase child care such that by 2010 quantity and quality would meet West European standards. This target was reinforced in December 2008, when the German government announced that by 2013 all children age 1 and older should possess of a legal claim for a child care slot ("Kinderförderungsgesetz", law on support for children). As a consequence, child care availability rose quite substantially over the following years. In 2008 (the latest birth cohort in our sample) average supply reached 12\% (see Table 1). Yet, there were still strong regional differences across as well as within states. Between 2002 and 2008, the expansion on the state level varied between 2 slots per 100 children in Bremen and 11 slots per 100 children in Rhineland Palatinate. Thus, regional differences in child care supply did not only persist, but got partially even reinforced. Average levels varied from $7 \%$ in Schleswig-Holstein and North-Rhine Westphalia to $18 \%$ in Hamburg. Within state differences amounted up to 24 slots per 100 children.

Figure 1 provides a graphical representation of the differences in child care supply across German counties in 2002. It conveys two messages. First, there is substantial heterogeneity 
across West German counties. Figure 2 shows moreover that deviations from the state mean are substantial. Second, Figure 1 also shows that East German regions are not constrained in terms of supply. As a result, child care supply can not be used as an instrument for child care attendance in East Germany. Our analysis focuses therefore on West Germany only.

Where do these regional differences in child care supply stem from? States are responsible for the regulation of child care, while counties (238 across West Germany) are in charge of its implementation and organization. The process of opening up new child care slots has three steps. First, regional authorities project the demand as well as the potential of expanding child care on a yearly basis. Factors which enter this projection are current fertility as well as female employment, but also socio-economic conditions at the county level such as GDP per capita, unemployment rate, net migration and degree of urbanicity. Second, non-profit organization submit their proposals to set up new centers. Third, authorities at the state level must approve the submitted proposals. Approval is necessary for receiving subsidies from the state, which allow providers of child care centers to keep fees at very low levels (0-25\% of operating costs).

Given this lengthy administrative process, the expansion of child care does not only depend on demographic and socio-economic conditions of each county, but also on idiosyncratic shocks to the administrative process. Reasons for a deviation from the projected demand are, for instance, delays in approval, rejection of applications due to non-compliance with quality regulations, as well as shortages in qualified teachers or construction ground. Our identification strategy relies exactly on this idiosyncratic component of child care supply. To be more precise, our empirical analysis uses the intra-state variation of slots available at birth, net of key predictors of local child care demand (fertility, female employment, unemployment, GDP per capita, migration and degree of urbanicity) as an instrument for child care attendance.

To deal with the severe shortages in supply, centers operate with waiting lists giving preference to families who sign up their children early. Criteria which allow children to jump the waiting lists are the working status of their parents, single parenthood and siblings who are already enrolled in child care. Yet, considering excess demand and the need to register very early, rationing favors children from advantaged families - a fact further discussed in Section 5. Parents whose children do not get a slot in center-based care face two options: they can either keep their child at home until Kindergarten starts (age 3 years) or purchase very expensive informal care on the market. The costs of informal care exceeds the fees of centers by far. Public subsidies amount on average to $78.3 \%$, while parental fees cover only $17.9 \%$ of the total operating costs (13.4 billion Euros in 2003). In addition, parental fees depend on family size and income in a progressive manner. They amount to $0-25 \%$ of operating expenses which in 2002 amount on average to 2783 Euros per child and month. As a result, informal care is not a very common alternative (only $8.9 \%$ of the families in our data rely on nannies on a frequent basis, and only $2.1 \%$ do so on a part- or fulltime basis). 
Figure 1: Child care slots per 100 children under age 3 years, 2002

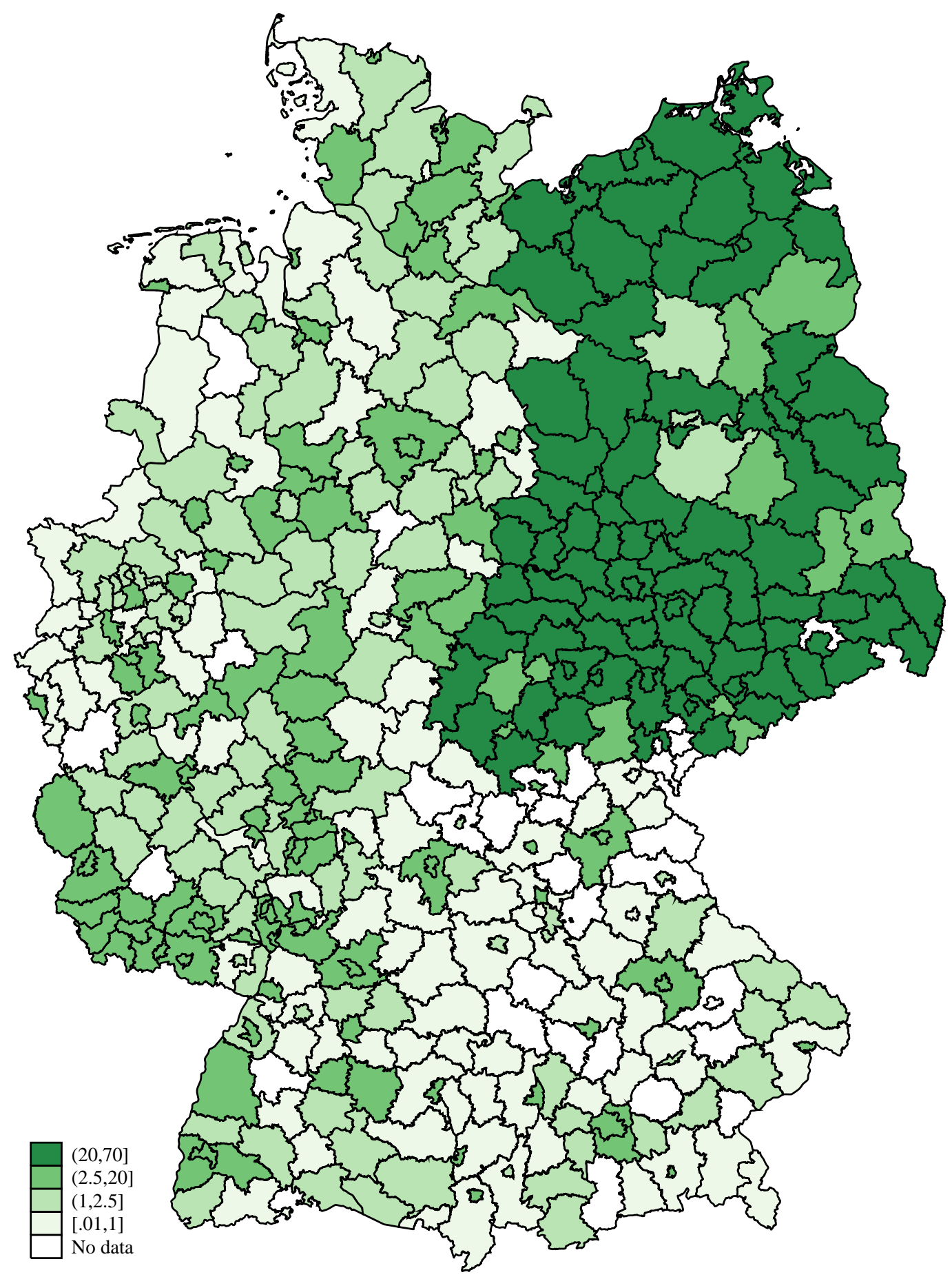

Notes: The Figure reports the number of slots available per 100 children age 0-3 for each county in Germany. Information is missing for areas shaded white.

Source: Kinder- und Jugendhilfe Statistik, Own calculations 
Figure 2: Child care slots - Deviations from state mean, West Germany, 2002

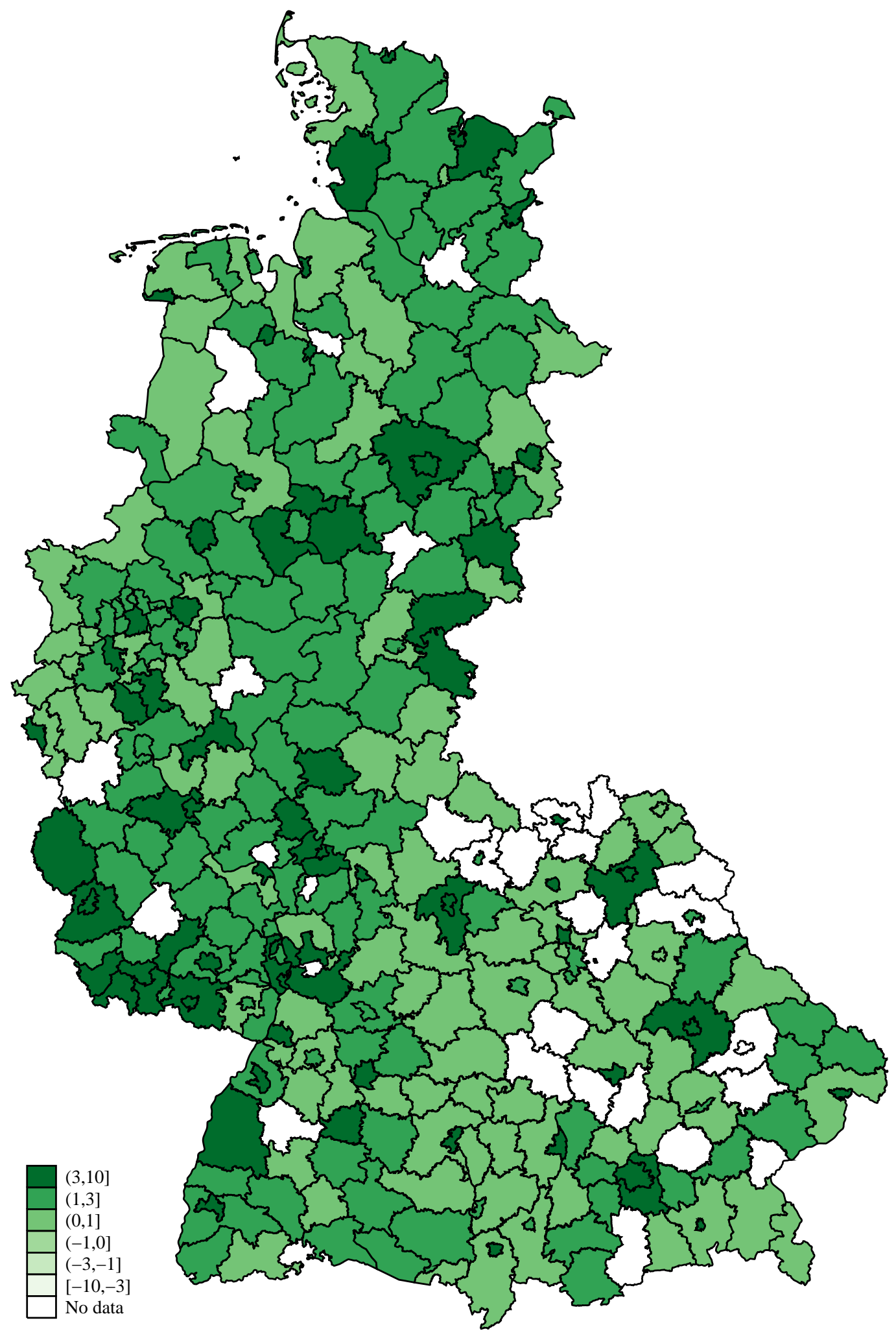

Notes: The Figure reports the deviations of each each county from the respective state mean in slots available per 100 children, age 0-3. Information is missing for areas shaded white.

Source: Kinder- und Jugendhilfe Statistik, Own calculations 
Besides providing care, centers have a clear educational mission. Educational goals concern developing skills related to pattern recognition as well as motor and language skill development. Center staff develop these skills using educational and playful activities in support of these skills. Moreover, center-based care is also expected to contribute to the development of social skills such as interacting with others, calling other people by their name, etc. Regulations, which fall into the jurisdiction of the states, concern dimensions such as opening hours, group sizes, staff-child ratios, but also qualifications of the staff before being allowed to work in the sector. Table 2 provides an overview of the actual implementation of selected measures.

Table 2: Quality measures of child care across West German states in 2007

\begin{tabular}{lccc}
\hline \hline & Fulltime slots & Child-Staff Ratio* & Pedagogical degree \\
\cline { 2 - 4 } Baden Wuerttemberg & 26.8 & 3.63 & 86.9 \\
Bavaria & 21.4 & 3.93 & 89.6 \\
Bremen & 35.7 & 3.17 & 79.8 \\
Hamburg & 29.4 & 5.09 & 93.4 \\
Hesse & 42.3 & 4.23 & 86.7 \\
Lower Saxony & 79.0 & 3.81 & 95.2 \\
North-Rhine-Westphalia & - & 2.76 & 92.9 \\
Rhineland-Palatinate & 57.1 & 3.32 & 91.6 \\
Saarland & 48.3 & 3.24 & 94.9 \\
Schleswig Holstein & 46.9 & 3.90 & 94.0 \\
\hline \hline
\end{tabular}

* Child- Staff ratio is currently only available for 2010.

Source: All numbers are taken from Riedel et al. (2005) and Huesken (2010).

Operating hours of child care centers vary quite substantially across states: while in Bavaria only $21.4 \%$ of all child care slots are full-time slots, in Lower Saxony, this percentage amounts to $79.0 \%$. The share of full-time slots in the remaining states lies somewhere in between, but does not exhibit any clear geographical pattern. Substantial differences are also observable with respect to child-staff ratio. Lowest child-staff ratios are found in North-Rhine-Westphalia (2.76 children per staff), closely followed by Bremen, Saarland and Rhineland-Palatinate. In the remaining states child-staff ratios lie just below 4 children per staff member (with the exception of Hamburg). State regulations regarding the share of qualified staff are rather lax. Yet, across all West German states, the majority of the pedagogical staff possesses of an educational degree.

Overall, we can state several differences in child care quality across West German states. In order to address this heterogeneity we control not only for a set of state fixed effects, but also for interactions between state fixed effects and child care coverage. 


\section{$3 \quad$ Data and Descriptive Analysis}

\subsection{Data}

The empirical analysis draws upon the German Socio-Economic Panel (SOEP) which is an ongoing household panel in Germany. ${ }^{4}$ Starting with the birth cohort 2002 it conducts additional interviews with all women who gave birth in the respective year. It again interviews these women when their children are 2-3 years old. Our sample contains 870 2-3 years-old children who are born between 2002 and 2008 and live in West Germany. Our sample is restricted to children about whom we possess complete information at age 0-1 years and age 2-3 years, and for whom we have regional information on child care supply.

The mother-child questionnaires contains an assessment of the child development based on the Vineland Adaptive Behaviors Scales (VABS). In 1984, these scales were developed by child psychologists Sara Sparrow and Domenic Cicchetti as a tool to diagnose development problems and have since become one of the most frequently used tool in child development research. The VABS focuses on one cognitive skill (language or communication skills), one non-cognitive skill (social skills), and two skills that refer to daily living and motor development (daily and motor skills). We can therefore discuss how child care affects a comprehensive range of development measures. The VABS scale is reported to have high internal consistency with correlations ranging from 0.8 to 0.95 across the four domains. The validity of these scales has been demonstrated by several studies (Sparrow and Cicchetti, 1985).

Mothers assess the developmental dimensions by responding to a series of 20 statements on the skills of their children. For instance, the first item concerning language skills is the statement "My child can form two word sentences." Mothers assess this skill on a qualitative scale with three levels: the statement is true (1), partially true (2), and (3) not at all true. The advantage of using motherly reports is that children are assessed in their natural environment by someone who knows them very well. Yet, the key disadvantage is that motherly reports can be prone to reporting bias. For instance, mothers who use center-based care may evaluate their children better to appease their bad conscience. While we can not rule out such source of bias, we believe that it is less of a problem for the measures that we analyze than it would be for others. The items in the VABS battery are based on factual questions. In contrast, questions regarding the subjective well-being or a child's personality would be more sensitive to reporting bias. Voelker et al. (1997) compare mother reports to teacher reports and find that teachers are more optimistic than care-givers in terms of the mean assessment on the VABS scale. Yet teacher and caregiver reports on the VABS scales are strongly positively correlated.

How are these skills related to later success in life? One may argue that many of these skills

\footnotetext{
${ }^{4}$ For more details please refer to Wagner et al. (2007)
} 
refer to dimensions that everyone learns at some point. This critique is certainly important and indeed, we find a child's age to be one important predictor of these skill measures. Nevertheless, mastering a certain skill earlier than the peer group may be beneficial in terms of self-confidence and thus may boost further skill development (Cunha et al., 2006). Moreover, Schatz and Hamdan-Allen (1995) document a robust correlation between VABS and IQ. Szatmari et al. (2003) document that age 4 to 6 years VABS communication skills are found to be significantly correlated with age 10 to 13 years communication skills. An improvement on the VABS is arguably likely to signal an improvement on later life labor market success.

\subsection{Descriptive evidence}

Do children with some exposure to child care differ from children with no time in child care? Table 3 reports the proportion of children who master each skill. In particular, we evaluate the probability that children master each skill dimension fully (true versus the rest). Column "All" is the sample average, column "Center" refers to children with at least one hour in center-based care, and column "No Center" refers to children who do not spend any time in a child care center. The table lists the least challenging skill first, and the most challenging skill last. ${ }^{5}$

Table 3, Panel A indicates that almost all children understand short sentences and form sentences with at least two words. Transmitting short messages, forming full sentences, and listening for five minutes or more is more challenging. Children in care are more likely to understand simple messages and to form full phrases and to listen to a story for more than five minutes. Turning to social skills, Table 3, Panel B shows that almost all children call familiar people by their names. More challenging are skills such as playing with other children, referring to own emotions, having favorite friends, and participating in role play. Significantly more children in care master the challenging tasks than children with no exposure to child care. Daily skills seem to be more challenging to children aged 2 to 3 years than both language and social skills (Table 3, Panel C). But again children who attend child care are significantly more likely to be able to master such skills, such as eating with a spoon, using the toilet to do number 2, and dressing alone. In terms of motor skills, Table 3, Panel D indicates that most children know how to open a door and walk down stairs forward. Climbing, using scissors, and, especially, painting are much more challenging than the first two skills. Again, children with some child care exposure know better how to climb and use scissors. The overall pattern of this first descriptive evidence indicates that children who spend some time in center-based care contrast favorably to children who do not experience any time in center-based care.

The effects of center-based care may depend i) on the care mode that is crowded out and ii) on the generated income due to increased maternal labor supply. Table 4 contains information

\footnotetext{
${ }^{5}$ Note we provide simple descriptive evidence at this stage being fully aware that selection into child care introduces significant bias into the prima facie comparison.
} 
Table 3: Center-based care and child development

\begin{tabular}{|c|c|c|c|c|c|}
\hline Does your child ... (label) & All & Center & No Center & Diff & z-Ratio \\
\hline \multicolumn{6}{|l|}{ A. Language Skills } \\
\hline ... understand short sentences (Understands) & .972 & .980 & .968 & .011 & $(.979)$ \\
\hline ... form short sentences (ShortPhrase) & .934 & .940 & .932 & .008 & $(.458)$ \\
\hline ... transmit short messages (ShortMsg) & .890 & .933 & .867 & .066 & $(2.972)$ \\
\hline ... form long phrases (LongPhrase) & .724 & .803 & .683 & .120 & $(3.777)$ \\
\hline ... listen to a story for min. 5min. (ListenStory) & .680 & .756 & .641 & .115 & $(3.471)$ \\
\hline \multicolumn{6}{|l|}{ B. Social Skills } \\
\hline .. call familiar people by their names (UsesNames) & .985 & .980 & .988 & -.008 & $(-.901)$ \\
\hline ... play with other kids (PlaysKids) & .877 & .926 & .851 & .075 & $(3.227)$ \\
\hline ... refer to own emotions (TalksEmotions) & .771 & .833 & .739 & .094 & $(3.14)$ \\
\hline ... have friends (HasFriends) & .731 & .819 & .685 & .135 & $(4.293)$ \\
\hline ... participates in role play (RolePlay) & .683 & .773 & .636 & .137 & $(4.155)$ \\
\hline \multicolumn{6}{|l|}{ C. Daily Skills } \\
\hline ... eat with a spoon (EatsSpoon) & .611 & .662 & .585 & .077 & $(2.225)$ \\
\hline ... brush her teeth (BrushesTeeth) & .437 & .421 & .445 & -.023 & $(-.661)$ \\
\hline ... clean her nose by herself (CleansNose) & .424 & .438 & .417 & .021 & $(.604)$ \\
\hline ... uses toilet for "no. 2" (ToiletNo2) & .391 & .468 & .35 & .118 & $(3.405)$ \\
\hline ... dress by herself (DressesAlone) & .284 & .341 & .254 & .087 & $(2.717)$ \\
\hline \multicolumn{6}{|l|}{ D. Motor Skills } \\
\hline ... open doors by herself (OpensDoor) & .960 & .977 & .951 & .026 & $(1.828)$ \\
\hline ... walk down stairs forward (WalksStairs) & .930 & .943 & .923 & .02 & $(1.108)$ \\
\hline ... climb playground items (Climbs) & .779 & .819 & .758 & .061 & $(2.066)$ \\
\hline ... use scissors (UsesScissors) & .594 & .706 & .536 & .170 & $(4.905)$ \\
\hline ... paints recognizable forms (Paints) & .331 & .331 & .331 & .000 & $(.003)$ \\
\hline Children & 870 & 299 & 571 & & \\
\hline
\end{tabular}

Notes: This table reports the share of children who master the specific skill, listed in descending order of difficulty. Column "All" is the sample average, column "Care" refers to children with at least one hour in care, and column "No Care" refers to children who do not spend any time in a child care center. The first column displays the label of each skill dimension which will be used thereafter.

Source: SOEP, own calculations. 
Table 4: Underlying mechanisms

\begin{tabular}{lccccc}
\hline \hline & All & Center & No Center & Diff & z-Ratio \\
\cline { 2 - 6 } A. Child care (hrs per week) & & & & & \\
Center & 6.377 & 18.555 & 0.000 & 18.555 & $(37.882)$ \\
Mother & 42.750 & 39.000 & 44.708 & -5.708 & $(-4.845)$ \\
Family & 19.218 & 18.435 & 19.631 & -1.196 & $(-.857)$ \\
Informal & 1.527 & .452 & 2.093 & -1.642 & $(-4.013)$ \\
B. Quality of motherly care & & & & & \\
Cognitive activities & .518 & .554 & .499 & .055 & $(2.385)$ \\
Motor activities & .366 & .336 & .382 & -.046 & $(-1.911)$ \\
Passive activities & .201 & .166 & .220 & -.054 & $(-2.515)$ \\
C. Labor supply and income & & & & & \\
Work (hrs per week) & 9.602 & 12.511 & 8.077 & 4.434 & $(4.557)$ \\
Gross income (EUR/month) & 602.818 & 865.644 & 466.874 & 398.771 & $(4.715)$ \\
Net income (EUR/month) & 3025.504 & 3276.758 & 2896.62 & 380.138 & $(3.156)$ \\
\hline Children & 870 & 299 & 571 & & \\
\hline \hline
\end{tabular}

Notes: This table reports information on alternative care modes (in hours per working week), mother-child interactions ( $=1$ if performed on a daily basis) as well as mothers' labor supply indicators (working hours per week, gross monthly income and household net income). Column "All" is the sample average, column "Care" refers to children with at least one hour in care, and column "No Care" refers to children who do not spend any time in a child care center. Cognitive activities refer to reading, singing, painting, or watching picture books. Passive activities refer to running errands and watching TV with the child. Motor activities refer to walking or going to the playground. Table shows the probability of doing the activity on a daily basis.

Source: SOEP, own calculations.

on alternative care modes (measured in hours per working week), ${ }^{6}$ mother-child interactions (represented by a binary variable which equals one if the mother performs the respective activity on a daily basis) as well as mothers' labor supply (expressed by mothers' working hours per week, mothers' gross monthly income and household net income).

When attending center-based care, children spend there on average 18.6 hours per week, but 5.7 hours less with their mothers and 1.6 hours less with a child minder. Mothers who send their

\footnotetext{
${ }^{6}$ The mother-child questionnaires contains a battery of questions inquiring the hours spent with different care providers. It does, however, not contain a question asking directly how many hours per week the child spends with the mother. For this purpose we rely on the time use survey contained in the personal questionnaires of the SOEP which reports the hours a women spends on child care. Notice, however, that this information must not necessarily relate to the child under study. A sizeable fraction (around $10 \%$ ) of mothers answer to this question that they devote 24 hours to child care. Given that average sleeping time among 2-3 years-old children amounts to 12 hours, we censor motherly care at 12 hours per day.
} 
Table 5: Selection into center-based care

\begin{tabular}{lccccc}
\hline \hline & All & Center & No Center & Diff & z-Ratio \\
\cline { 2 - 6 } A. Child Characteristics & & & & & \\
Child's age & 2.776 & 2.883 & 2.720 & .163 & $(7.195)$ \\
Low Birth Weight & .074 & .060 & .081 & -.020 & $(-1.092)$ \\
Boy & .506 & .515 & .501 & .014 & $(.397)$ \\
B. Mom's Characteristics & & & & & \\
Mom's age & 30.997 & 31.819 & 30.566 & 1.254 & $(3.336)$ \\
Mom is married & .724 & .696 & .739 & -.043 & $(-1.360)$ \\
Nr of siblings & .989 & .987 & .989 & -.003 & $(-.039)$ \\
High educated mom & .378 & .492 & .319 & .173 & $(5.062)$ \\
High household net income & .569 & .659 & .522 & .137 & $(3.904)$ \\
C. County Characteristics & & & & & \\
Fertility rate & & & & & \\
Female employment rate & 4.385 & 1.364 & 1.397 & -.033 & $(-4.206)$ \\
Unemployment rate & 11.200 & 11.376 & 11.108 & .268 & $(.930)$ \\
GDP per capita & 29.119 & 30.680 & 28.302 & 2.378 & $(2.607)$ \\
Net migration rate & 2.320 & 2.409 & 2.274 & .135 & $(.496)$ \\
Degree of urbanicity & .544 & .569 & .531 & .038 & $(1.066)$ \\
\hline Children & 870 & 299 & 571 & & \\
\hline \hline
\end{tabular}

Notes: This table reports individual family and regional background characteristics. Column "All" is the sample average, column "Care" refers to children with at least one hour in care, and column "No Care" refers to children who do not spend any time in a child care center.

Source: SOEP, own calculations.

child to child care are 5.5 percentage points more likely to do cognitive stimulating activities with their children on a daily basis (reading, singing, painting, or watching picture books) and 5.4 percentage points less likely to run errands when their children are around (running errands and watching TV). Finally, mothers whose children are in center-based care, work on average 4.4 hours more per week - a fact highlighting that there is not a one-for-one translation of child care into maternal labor supply - and as a consequence earn 399 Euros more per month. Evidence so far points to an important development advantage for children who attend child care. Yet, these two groups of children might also be different in other dimensions. We therefore turn now to contrasting children in terms of their background characteristics.

Table 5, Panel A and B show clear evidence for selection into center-based care. Children with some exposure to center-based care are about two months older and their mothers are 1.3 years 
older than children and their mothers with no center-based care experience. This differences is largely mechanical since the decision to enter center-based care is often taken while the child is 2 years old. Yet, there are also differences in terms of the socio-economic status (SES). Children with some center-based care exposure tend to have better educated mothers (17 percentage points more likely to have secondary or university level education) and live in richer households (14 percentage points more likely to have a net household income at birth of 2250 Euros per months or more) than children with no exposure to center based care. This evidence is consistent with rationing favoring high SES children.

Table 5, Panel $\mathrm{C}$ discusses the characteristics of the county the child was born. Notice, that we condition on the characteristics of the county of birth since post-birth migration might be endogenous. ${ }^{7}$ Families whose children attend center-based care live in regions with higher female employment and higher GDP per capita, but lower fertility compared to families whose children spend no time in center-based care. ${ }^{8}$ The likelihood to live in an urban area does not correlate with child care attendance. Taken together, the evidence in Table 5 suggests that it is important to control for selection on observable characteristics.

\section{Econometric Framework}

This section introduces the econometric framework to estimate marginal treatment effects (MTE) of child care on child development. We discuss MTE in the same framework as Carneiro et al. (2011) who discuss marginal returns to education.

\subsection{Setting the Stage}

We first introduce notation. The treatment we analyze is some exposure to child care versus no exposure to child care. Let $D_{i}=1$ if child $i$ spends at least some hours per week in the child care center, and $D_{i}=0$ otherwise. ${ }^{9}$ Associated with these two situations are potential outcomes. $Y_{1 i}^{s}$ is the child development measure in dimension $s$ of child $i$ exposed to center-based care, where $s$ denotes language, social, daily and motor skills. $Y_{0 i}^{s}$ is the corresponding child development score for the same child without exposure to center-based care.

\footnotetext{
${ }^{7}$ We have also explored pre-birth migration and find that it is unrelated to child-care offer rates.

${ }^{8}$ Regarding the concern that fertility might be endogenous to child care supply, notice that the fertility rate does not correlate with individual child care attendance, see Table 6. Moreover, results using child care supply three years prior to child birth as the instrument are qualitatively the same and are available upon request.

${ }^{9} \mathrm{We}$ focus on the extensive margin in this paper for simplicity. We believe that understanding the intensive margin is also important but we leave this to future research.
} 
We assume the following linear-in-parameters specifications for the potential outcomes

$$
\begin{aligned}
& Y_{1}^{s}=X \beta_{1}^{s}+U_{1}^{s} \\
& Y_{0}^{s}=X \beta_{0}^{s}+U_{0}^{s}
\end{aligned}
$$

This specification embeds a good trade-off between flexibility and specificity. On the one hand, the model is very specific in terms of how observed and unobserved components affect potential outcomes. We assume with this linear index specification that the component due to unobserved characteristics is separable from the component due to observed characteristics. On the other hand, the model is very flexible in terms of the effects of child care. These may vary across children both in terms of their observed and unobserved characteristics.

The model is closed by a specification representing selection into child care, or put it differently, a specification representing the choice of parents to send their child to child care:

$$
D=I\left(X \pi_{X}+Z \pi_{Z}-V>0\right)
$$

The selection process depends on observable characteristics $X$, such as child, family and regional features. Importantly, we also add the number of child care slots in the county in the year the child was born, as the key county level determinant of whether a child is enrolled in child care $(Z) .{ }^{10}$ Finally, we also allow for unobserved components $V$ to enter the selection process. Notice that the linear specification implies monotonicity, the key assumption needed to interpret IV estimates in heterogeneous treatment effects models (see Vytlacil, 2002).

The probability of selection into child care - the propensity score $P(W)$ - is then as follows $P(W)=\operatorname{Pr}(D=1 \mid Z=z, X=x)=\operatorname{Pr}\left(X \pi_{X}+Z \pi_{Z}-V>0\right)=\operatorname{Pr}\left(F_{V}\left(X \pi_{X}+Z \pi_{Z}\right)>U_{D}\right)$

where $F_{V}(\cdot)$ is the cumulative density of unobserved characteristics $V$, and $U_{D} \equiv F_{V}(V)$ is uniformly distributed by construction and represents different quantiles of $\mathrm{V}$.

\subsection{Identification}

The MTE represents the effect of attending child care for children who are just indifferent between attending child care and not attending child care, i.e. for children belonging to a specific quantile of the unobserved component of the propensity to attend child care $\left(U_{D}=u\right)$ :

\footnotetext{
${ }^{10}$ Note, since we add the available slots at birth, and thus at least one year prior to child care attendance, our first stage - explaining individual child care exposure by aggregate child care slots - does not suffer from the "reflection problem", i.e. the mechanical positive correlation between individual formal care attendance and county mean formal care attendance (Manski, 1993). It also circumvents any potential relation between child care supply and post-birth mobility. In any case, further analysis of migration in the years around child birth does not reveal any pattern that migration is driven by child care supply. Results are available upon request.
} 


$$
E\left(Y_{1}^{s}-Y_{0}^{s} \mid X=x, U_{D}=P(w)\right)=x\left(\beta_{1}^{s}-\beta_{0}^{s}\right)+E\left(U_{1}^{s}-U_{0}^{s} \mid X=x, U_{D}=P(w)\right)
$$

Tracing the MTE allows us to understand how the returns to child care attendance vary with respect to observable characteristics as well as across different quantiles of the unobserved component of the propensity to attend child care. The key assumption to identify this parameter is conditional independence of $Z$ - local child care supply - from the unobserved components of the potential outcomes and the selection equation:

$$
Z \mid X \Perp U_{1}^{s}, U_{0}^{s}, U_{D}
$$

Is this assumption credible in our context? In the presence of state fixed effects, our analysis exploits deviation in child care supply from the state mean. As discussed in Section 2, once we control for important predictors of local child care demand - fertility, female employment, unemployment, GDP per capita, migration and degree of urbanicity - the remaining variation in supply reflects deviations from predicted demand and thus is the result of idiosyncratic shocks, such as wrong projections of demand, delay in approval, or capacity constraints regarding pedagogical staff or construction grounds. Thus, conditional on observable county characteristics as well as a set of state fixed effects, local supply is arguably independent of $\left(U_{1}^{s}, U_{0}^{s}, V\right)$.

One important consequence of the conditional independence assumption is that we can express the conditional expectation of an observed measure of child development as follows

$$
\begin{aligned}
E\left(Y^{s} \mid X=x, P(W)=p\right) & =x \beta_{0}^{s}+p x\left[\beta_{1}^{s}-\beta_{0}^{s}\right]+E\left(U_{0}^{s}+D\left(U_{1}^{s}-U_{0}^{s}\right) \mid X=x, P(W)=p\right) \\
& =x \beta_{0}^{s}+p x\left[\beta_{1}^{s}-\beta_{0}^{s}\right]+K_{x}^{s}(p)
\end{aligned}
$$

To see this note that conditional independence of $U_{0}^{s}$ from $Z$ implies that $E\left(U_{0}^{s} \mid X=\right.$ $x, P(W)=p)=0$. Conditional independence of $\left(U_{1}^{s}, s_{0}, U_{D}\right)$ from $Z$ also implies that $E\left(D\left(U_{1}^{s}-\right.\right.$ $\left.\left.U_{0}^{s}\right) \mid X=x, P(W)=p\right)=p E\left(U_{1}^{s}-U_{0}^{s} \mid X=x, P(W)=p\right) \equiv K_{x}^{s}(p) . K_{x}^{s}(p)$ is an unknown function that measures how the mean of the unobserved component of the treatment effect $U_{1}^{s}-U_{0}^{s}$ varies with the propensity score.

The MTE is the partial derivative of (7) with respect to the propensity score (Heckman and Vytlacil, 2000):

$$
\begin{aligned}
E\left(Y_{1}^{s}-Y_{0}^{s} \mid X=x, U_{D}=u\right) & =\frac{\partial E\left(Y^{s} \mid X=x, P(W)=p\right)}{\partial p} \\
& =x\left[\beta_{1}^{s}-\beta_{0}^{s}\right]+E\left(U_{1}^{s}-U_{0}^{s} \mid X=x, P(W)=p\right)
\end{aligned}
$$




\subsection{Estimation}

Estimation of the MTE is not straightforward. In practice, it is very difficult to condition on $X$ non-parametrically by conducting the above analysis within cells defined by $X$. Carneiro et al. (2011) suggest imposing the additional assumption

$$
(X, Z) \Perp\left(U_{1}^{s}, U_{0}^{s}, U_{D}\right)
$$

This assumption implies that the unobserved component of the MTE no longer varies across groups with different values of $X$, i.e. $K_{x}^{s}(p)=K^{s}(p)$. This assumption is clearly a strong one. We will therefore provide estimates that depend on this assumption to be true. We also provide estimates within two subsamples defined by combinations of $X$. Specifically, we divide the sample according to the estimated linear index in the equation that predicts child care attendance, $X \pi_{X}$. The high score sample is the one with $X \pi_{X}$ exceeding the mean, the low score sample is that with $X \pi_{X}$ smaller or equal to the mean. We then estimate model (7) separately in the two sub-samples and aggregate the results thereafter. This allows us to see whether the main estimates are sensitive to assuming the stronger identifying assumption. ${ }^{11}$

We proceed estimating the reduced form (7) using two alternative approaches: a polynomial and a partial linear approach. The first approach introduces polynomials of the propensity score $p$ of order two or higher into (7). ${ }^{12}$ The partial linear approach recognizes that the model (7) contains a parametric and a non-parametric component which can be estimated in the following steps. First, all characteristics in $X$ are regressed on $p$ using kernel regression. This step provides the $p$-residuals of $X$, i.e. $X_{p}=X-\hat{X}$. Second, $Y$ is regressed on $X_{p}$ thus cleaning the influence of observed characteristics from $Y$. This step provides $Y$ residuals that are orthogonal to observed characteristics $X$, i.e. $Y_{X}=Y-\hat{Y}$. Finally, $Y_{X}$ residuals are non-parametrically regressed on $p$ providing an estimate of $K(p)$. The MTE is then obtained by calculating local linear estimates of the first derivative of $K(p)$ with respect to $p$.

\section{Results}

This section presents the main empirical results. We start by discussing the propensity score estimates to discuss selection into child care as well as the strength of our instrument. Section 5.2 then reports MTE estimates which allow for a discussion of effect heterogeneity with respect to observable and unobservable components. Section 5.3 discusses implications for two different policy scenarios. Section 5.4 continues presenting linear instrumental variable estimates. Finally, Section 5.5 discusses mechanisms underlying the effects of child care on child development.

\footnotetext{
${ }^{11}$ Note that this sub-sample analysis may not detect failures of the assumption (9) in our sensitivity check since sub-samples are formed based on a linear index of $X$ rather than the values of $X$ themselves.

${ }^{12}$ The polynomial approximation converges to the unknown function $K(p)$, representing the unobserved component in the propensity score function asymptotically.
} 
Figure 3: Center-based care attendance vs offer rate

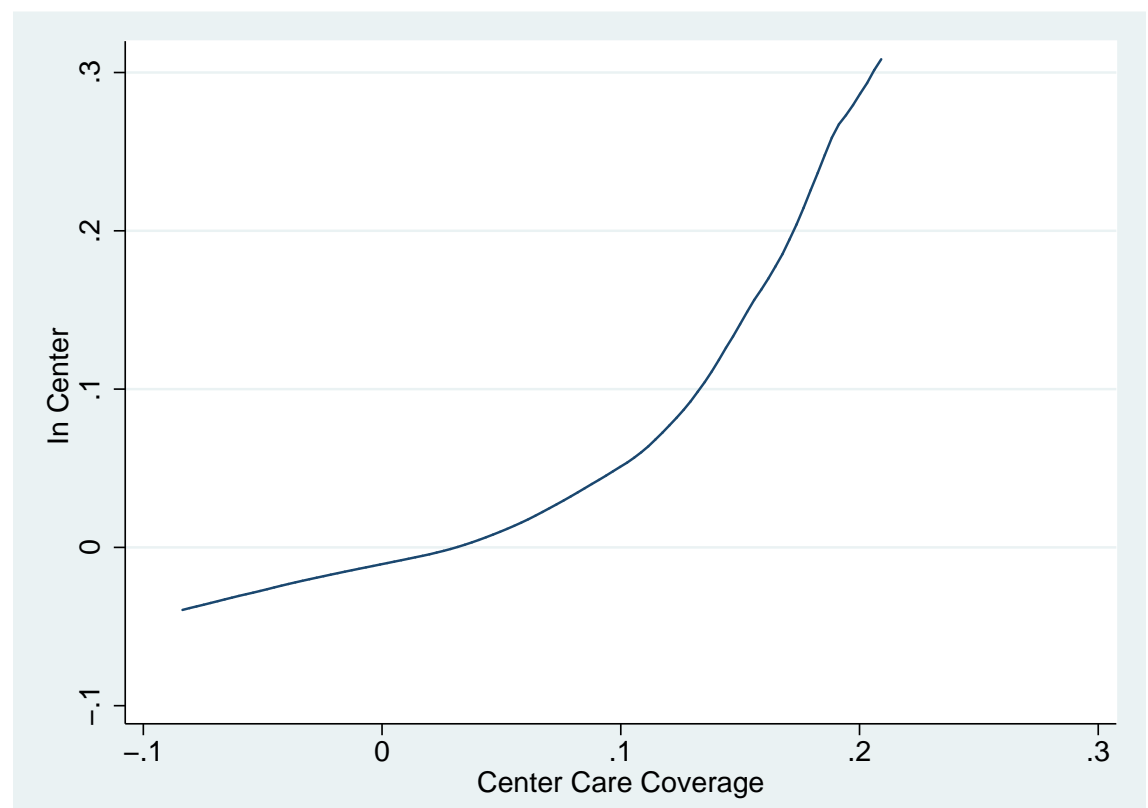

Notes: This graph plots child care attendance vs the county level offer rate. Both measures are expressed as deviation from the respective state mean. The graph is produced using kernel regression (Epanechnikov kernel, bandwidth of $0.2,100$ grid points).

Source: SOEP, Own calculations

\subsection{Propensity Score}

The propensity score and its support are central to any treatment effects analysis. The key component of the propensity score is the local child care offer rate. In a situation of excess demand, it should be highly predictive of individual child care attendance. We first present descriptive evidence on the relationship between the child care offer rate and individual attendance.

Figure 3 plots a kernel regression of the proportion of children in center-based care at age 2-3 years with respect to slots available to children age 0-3 years in the year of child birth. We focus on how within-state variation in the offer rate predicts within-state variation in individual participation since the empirical analysis conditions on state fixed effects throughout. Figure 3 shows that attendance increases about one-for-one with the available slots in the county. This is first evidence that county level supply is a key predictor of individual attendance.

What are the determinants of the propensity score? Table 6 reports linear probability model estimates of individual care attendance. ${ }^{13}$ Standard errors are clustered on the county level.

Estimates indicate that slots at birth are a strong predictor of individual center-based car

\footnotetext{
${ }^{13}$ Logit and Probit estimates of the propensity score (not shown but available upon request) provide a qualitatively similar picture. We adopt a linear probability model specification for the propensity score since it corresponds to the first stage in a two step least squares estimation of the effects of child care. This means that using $Z$ or the estimated propensity score as an instrument will deliver identical results.
} 
attendance. The marginal effect of slots at birth is positive and significantly different from zero. Interestingly, individual attendance increases by 17 percentage points if ten slots per 100 children are added. The hypothesis that individual attendance increases one-for-one with available slots at birth is not rejected by the data. ${ }^{14}$

Table 6 also provides interesting results concerning observable individual and regional determinants of care attendance. Older children are more likely to be enrolled in center-based care with a one year increase in age raising child care attendance by 35.4 percentage points. Highly educated mothers (secondary or university level) are 13.7 percentage points more likely to place their child in center-based care than mothers with a primary level degree or other degree. Moreover, families with net incomes exceeding 2250 Euros per month are more likely to find a slot in center-based care than families with lower net incomes (by 9.2 percentage points). Regional characteristics do not correlate with individual attendance. This suggests that bias due to unobserved county characteristics may not be important. Indeed, in the framework of Altonji et al. (2005), there is no bias due to unobserved county characteristics in our estimates.

In contrast, the "F-test Individual variables" clearly rejects the null hypothesis that child or mother characteristics are orthogonal to selection into care. This raises the possibility of a bias due to unobserved child or mother characteristics. For instance, highly educated women may be more likely to give birth in counties that offer lots of child care possibilities than in counties where the supply of child care is constrained. We explore whether unobserved individual characteristics bias results as follows. First, we select a range of supplementary variables that are not part of our standard set of control variables $X$ but likely predictors of child development: birth outcomes, indicators of mothers' parenting style and preferences. Second, we regress each of these measures separately on the county level supply of child care slots and the standard vector of controls $X$. A finding that the omitted predictors of child development are correlated with local supply of child care would be evidence against assumption (6).

Table 7 shows that child care supply is not correlated with a child's initial health conditions, such as height and head-circumference at birth. Child care slots are also conditionally orthogonal to mothers' attitudes towards child rearing or whether they perceive motherhood as something stressful. Finally, slots are also not correlated with mothers' patience or risk attitudes. These results are consistent with the local child care supply at birth being exogenous and not correlated with supplementary predictors of child development.

Figure 4 displays the probability density function of the estimated propensity score $p$, separately for children who attend and who do not attend center-based care. The support of the estimated propensity score is large for both treated and control children. Children who are

\footnotetext{
${ }^{14}$ We have also explored whether the relationship between individual care attendance and slots provided per 100 children is non-linear. This hypothesis is clearly rejected by the data. The individual probability of attending child care increases more than one-for-one because children typically share slots.
} 
Table 6: Estimates of the propensity score

\begin{tabular}{|c|c|}
\hline & Child Care Attendance \\
\hline \multirow[t]{2}{*}{ Slots at Birth } & $1.712^{* * *}$ \\
\hline & $(0.472)$ \\
\hline \multirow[t]{2}{*}{ Age of child in years } & $0.354^{* * *}$ \\
\hline & $(0.050)$ \\
\hline \multirow{2}{*}{ Child was low birth weight child } & -0.057 \\
\hline & $(0.057)$ \\
\hline \multirow[t]{2}{*}{ Child is a boy } & -0.006 \\
\hline & $(0.032)$ \\
\hline \multirow[t]{2}{*}{ Age of mom at child birth } & 0.004 \\
\hline & $(0.003)$ \\
\hline \multirow[t]{2}{*}{ Mom is married } & -0.041 \\
\hline & $(0.038)$ \\
\hline \multirow[t]{2}{*}{ Number of kids in the household } & -0.016 \\
\hline & $(0.016)$ \\
\hline \multirow[t]{2}{*}{ High education } & $0.137^{* * *}$ \\
\hline & $(0.037)$ \\
\hline \multirow[t]{2}{*}{ High income } & $0.092^{* * *}$ \\
\hline & $(0.031)$ \\
\hline \multirow[t]{2}{*}{ Urban area } & 0.027 \\
\hline & $(0.033)$ \\
\hline \multirow[t]{2}{*}{ Unemployment rate at childbirth } & 0.004 \\
\hline & $(0.005)$ \\
\hline \multirow[t]{2}{*}{ Female employment rate at childbirth } & 0.000 \\
\hline & $(0.001)$ \\
\hline \multirow[t]{2}{*}{ Fertility rate at childbirth } & 0.174 \\
\hline & $(0.199)$ \\
\hline \multirow[t]{2}{*}{ GDP per capita at childbirth } & -0.001 \\
\hline & $(0.002)$ \\
\hline \multirow[t]{2}{*}{ Net migration at childbirth } & -0.002 \\
\hline & $(0.005)$ \\
\hline F-test Individual variables & 0.000 \\
\hline F-test Regional variables & 0.797 \\
\hline F-test State dummies & 0.000 \\
\hline R-squared & 0.150 \\
\hline Children & 870 \\
\hline
\end{tabular}

Notes: This table shows linear probability model estimates of the propensity score. Slots at birth refer to the child care slots available per 100 children age 0-3 years old in the county at birth of the child. Estimates also include a full set of cohort dummies, state dummies and a constant term (not shown in the table). Standard errors are clustered at the county level and are shown in parenthesis: ${ }^{*} \mathrm{p}<0.10,{ }^{* *} \mathrm{p}<0.05,{ }^{* * *} \mathrm{p}<0.010$ 
Table 7: Child care supply and further key child development determinants

\begin{tabular}{lc}
\hline \hline & t-statistic \\
\hline Birth height & -1.026 \\
Birth head circumferences & 1.246 \\
Child rearing makes happy & -.324 \\
Motherhood is satisfying & -.872 \\
Tenderness is important & -.662 \\
Often Exhausted & .100 \\
New Tasks Difficult & 1.04 \\
Suffer from Limitation & -.779 \\
Risk aversion & .009 \\
Patience & -.940 \\
\hline
\end{tabular}

Notes: This table shows estimates of the partial correlation between the local child care supply and various measures of child and mother characteristics that do NOT figure in the list of control variables.

Source: SOEP, Own calculations

enrolled in formal care have characteristics $X$ or $Z$ that predict higher attendance probabilities than children who are not enrolled. The support of the estimated propensity score of the treated children overlaps the support of the propensity score of control children quite well. ${ }^{15}$

\subsection{Marginal Treatment Effects}

This section discusses the MTE. All estimates are based on the empirical specification 7 with one key distinction. We measure observed characteristics as deviations from sample means before they are interacted with the propensity score. This implies that the coefficients attached to the propensity score measure the MTE for children with average sample characteristics. Interaction terms measure how effects differ for subgroups with respect to the average MTE.

We first discuss whether and how the MTE depend on observed individual characteristics. Table 8 summarizes the findings for all skill dimensions- language, social, daily and motor skills highlighting for whom MTE are most pronounced. A negative sign indicates that the respective subgroup exhibits significantly lower returns to care attendance in at least one measure of the respective skill dimension. A positive sign works analogue, but indicates higher returns to care attendance for the respective subgroup. The bottom of the table displays in how many cases the following three hypotheses could not be rejected: i) heterogeneity with respect to individual

\footnotetext{
${ }^{15}$ At the bottom, we find four control observations that have propensity scores that are smaller than the minimal propensity score among the treated. There are fourteen treated children with scores greater than the maximal score among the control children.
} 
Figure 4: Overlap propensity score

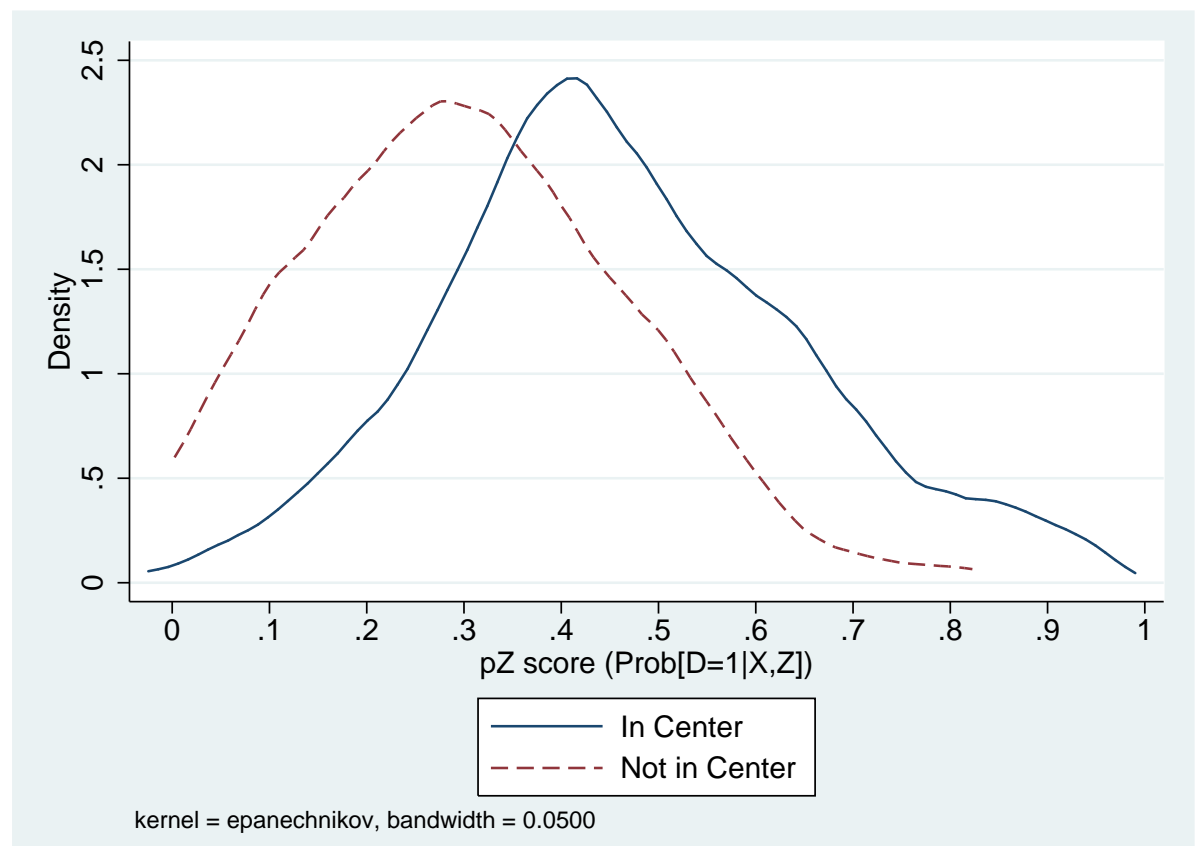

Notes: This graph plots the p.d.f. of the estimated propensity scores, separately for children with some exposure to center based care and children with no exposure to it.

Source: SOEP, Own calculations

characteristics (row "Het. Individual"), ii) heterogeneity with respect to regional characteristics (row "Het. Regional"), and iii) heterogeneity across states (row "Het. State"). Detailed results of the underlying reduced form regressions are shown in Appendix B (Table B.1 to Table B.4).

There exists substantial effect heterogeneity with respect to observable individual characteristics. Based on the "Het. Individual" test (see Table 8), we can reject the null hypothesis of joint insignificance of the interactions between the propensity score and individual characteristics for the majority of the child skill measures (for 3 out of 5 language skills, 2 out of 5 social skills, 2 out of 5 daily skills, and 3 out of 5 motor skills).

In particular, MTEs are significantly lower for older children, above all in terms of language and social skills. This result is consistent with many children learning the measured skills; there is less scope for child care to make a difference with older children than with younger ones. Nonetheless, the result indicates that there are significant returns to care attendance for younger children. Thus, early center-based care attendance boosts children's skills and thus might free up capacities to acquire already more advanced skills. Similarly, returns to child care in terms of language and social skills are decreasing in mothers' age. Child care attendance improves communication skills (in from of short messages or long sentences) and interaction in role plays for children with low birth weight helping them catch up with their normal birthweight peers. Child care also boosts the language and social skills of boys, in particular their ability to talk as 
well as to refer to their emotions. Children of married couples experience positive gains in terms of comprehension and walking down stairs forward. Children with siblings benefit more in terms of social and daily skills, in particular they are more likely to refer to their emotions, to interact in role plays and to dress alone. Children from an advantaged socio-economic background, in terms of maternal education and household net income, derive lower returns to child care attendance than children from a less advantaged family background. In particular, children from an advantaged background have lower returns to child care in terms of comprehension and independence (their ability to dress alone). One explanation might be that higher SES families invest already early on in their children's skills and thus, any benefits their children might derive from child care might not be captured by the available skill measures.

The results shown so far are highly relevant for a discussion on policies targeted at expanding center-based care. Comparing the MTE estimates (see Table 8) with the propensity scores estimates (see Table 6) reveals the following: children who have the lowest returns from attending child care are sent to child care first. Yet, children who would benefit the most - younger children and children from disadvantaged backgrounds - are least likely to be sent to child care.

What about heterogeneity in the MTE with respect to regional characteristics? The test "Het. Regional" reveals heterogenous treatment effects with respect to regional features, mainly in terms of language and daily skills (see Table 8). Specifically, MTE on language skills are particularly strong in regions with high migration rates. MTE for daily skills are particulary high in regions with high female employment and high fertility rates. These results suggest that child care effects are very much dependent on the local context. Turning to differences in the returns to child care across federal states, heterogeneity across states exists mainly in the dimension of language and social skills (see "Het. States" in Table 8).

We now discuss whether the MTE differ with respect to unobserved determinants of child care attendance. Figure 5 reports two estimates of the MTE. The "Polynomial" estimate represents the MTE based on a specification of the reduced form with second order terms of the propensity score. We plot this estimate along with its $95 \%$ confidence interval. The "Partial linear" estimate is a completely unrestricted partial linear estimate of the treatment effect.

The overall pattern resulting from the "polynomial" specification points towards increasing gains in unobserved determinants of child care attendance for basically all skill dimensions (with the exception of 1 measure among language and daily skills and 2 measures among social and motor skills). Thus, children who are the least likely to enter child care (in terms of unobserved features) have higher gains from attending child care in terms of social, language, daily and motor skills than children who face lower unobserved entry barriers.

We also discuss stratified estimates to assess whether our results are sensitive to relaxing the conditional independence assumption. Figure B in the Appendix B provides separate MTE estimates for children stratified by predicted probability of child care attendance. Specifically, 
Table 8: Child care and child development: Overview

\begin{tabular}{rcccc}
\hline \hline & Language & Social & Daily & Motor \\
\cline { 2 - 5 } A. Child's characteristics & & & & \\
Age child & - & - & & \\
Low birth weight & + & + & & \\
Boy & + & + & & \\
B. Mother's characteristics & & & & \\
Age mother & - & - & & \\
Married & + & & & + \\
Nr siblings & & + & + & \\
High Education & - & & - & \\
High Income & & & - & \\
Het. Unobserved & $0 / 5$ & $0 / 5$ & $1 / 5$ & $0 / 5$ \\
Het. Individual & $3 / 5$ & $2 / 5$ & $2 / 5$ & $3 / 5$ \\
Het. Regional & $2 / 5$ & $0 / 5$ & $2 / 5$ & $0 / 5$ \\
Het. State & $2 / 5$ & $4 / 5$ & $1 / 5$ & $1 / 5$ \\
\hline
\end{tabular}

Notes: This table summarizes the results of the reduced form estimates for language, social, daily and motor skills shown in Table B.1- B.4. A negative sign indicates that the respective subgroup exhibits significantly lower returns in at least one measure in the respective skill dimension, a positive sign works analogue but indicates higher returns in the respective subgroup. The rows referring to heterogeneity with respect to individual and regional features or states, indicate in how many cases the hypothesis test of joint significance of the respective interaction terms could not be rejected in the respective skill dimension.

Source: SOEP, Own Calculations. 
Figure 5: Marginal Treatment Effects (Evaluated At Avg. Child Characteristics X)

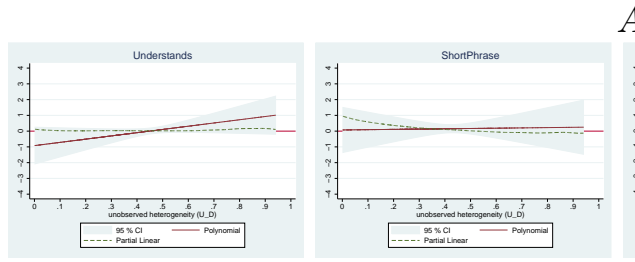

A. Language Skills
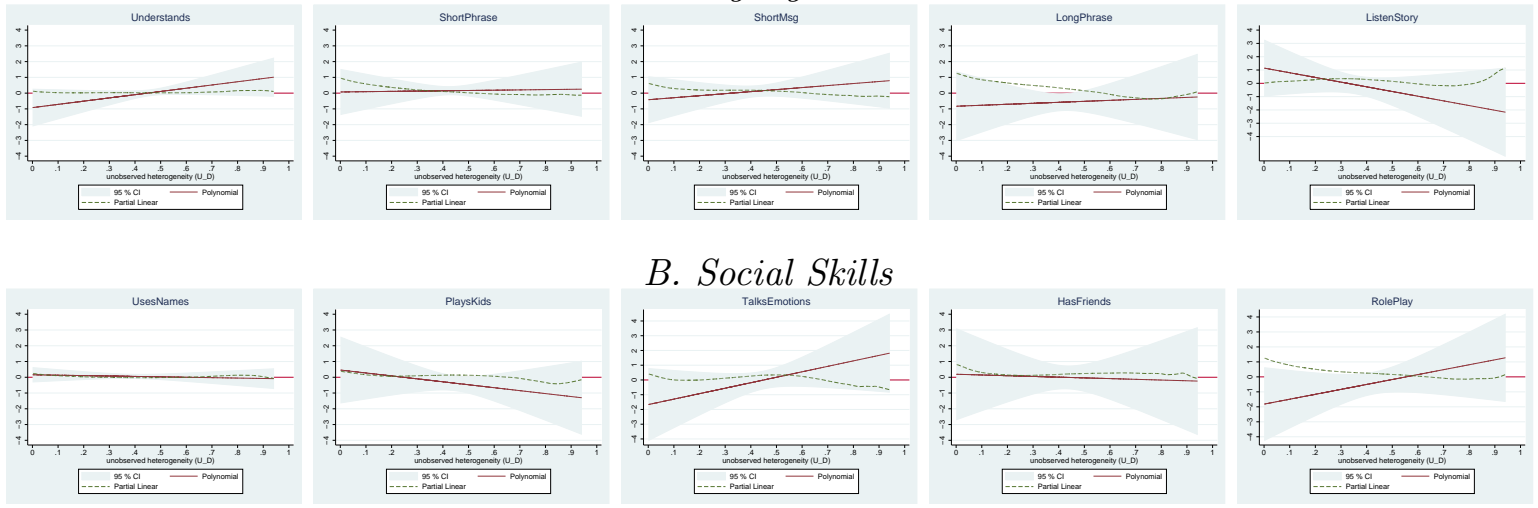

\section{B. Social Skills}
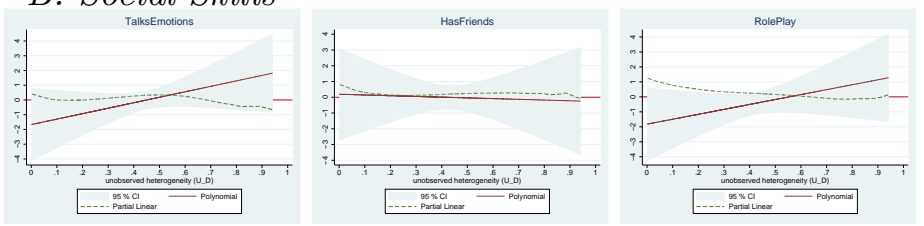

C. Daily Skills


D. Motor Skills

Notes: This Figure shows the effect of center-based care on the children who are indifferent between attending child care and not doing it. The Figure displays the component of the MTE that is related to unobserved characteristics $U_{D}$. The component that is related to observed characteristics is evaluated at the average child in the sample. The "Polynomial" estimate is based on a polynomial approximation to the unobserved component using a $2^{\text {nd }}$ order polynomial, the area shades the $95 \%$ confidence interval. The "Partial linear" estimate is based on a partial linear model estimate of the MTE.

Source: SOEP, Own Calculations 
we divide the sample at the mean of the estimated linear index predicting child care attendance (holding local child care supply fixed). ${ }^{16}$ Stratified estimates suggest that the baseline estimates are valid estimates of the average effect of attending childcare for more than three out of five skills in all four skill dimensions. Stratified estimates also reveal that the child care returns are increasing with unobserved entry barriers for children who are simultaneously less likely to attend child care in terms of observable characteristics.

Yet, our small sample prevents us from rejecting the null hypothesis of a constant MTE: the confidence interval of the "polynomial" estimates contains almost always the zero (except some small areas among 2 measures of daily skills). The tests of heterogeneity with respect to unobservables (shown in Table 8, "Het. Unobserved") are likewise all rejected. Partial linear estimates reveal no general pattern: estimates alternate very closely around zero. Hence, these results suggest that there is no heterogeneity in the MTE with respect to unobservables.

\subsection{Effects under Alternative Policy Scenarios}

Do effects differ between children who are currently enrolled and children who only enroll once supply constraints are lifted? In other words, is there effect heterogeneity between treated children and children only being treated once more slots open up? To answer this question we simulate the effects of two alternative policies (please refer to Appendix A.1, for details): first, a policy which simulates an increase in child care slots from zero to the level that we currently observe in each county, and second, a policy which leads to a further expansion from the current level to full coverage - or 40 slots per 100 children. $^{17}$

The simulation of both policies is based on comparing the expected value of the set of skill dimensions after the respective reform with the counterfactual outcome in the absence of the reform for each child. We then calculate the average impact of this policy for the entire population of children. Standard errors are based on a bootstrap procedure with 250 repetitions. Table 9 shows the estimated effects of such policies on children's skill development.

Comparing the two alternative policies reveals interesting results. The expansion from zero slots in child care facilities to the current stock seems to have rather negative effects: only 6 out of 20 skills are positively affected by such an expansion of child care slots. Thus, benefits due to child care do not outweigh potential delays in the development of certain skills for children

\footnotetext{
${ }^{16}$ Notice that we can only estimate MTE for those areas of the propensity score for which we have empirical support in the respective subsample. As a result, for the "low score" sample (those who exhibit a propensity lower than the median linear index) we can only estimate MTE within the range of 0.00 and 0.67 and for the "high score" sample only within a range of 0.25 and 1.00 .

${ }^{17}$ Full coverage for children aged 0 to 3 years is attained at a coverage level much below $100 \%$. Few children below the age of one year are placed in center based care. Children in the range 1 to 3 years are in half day care so they share a slot with another child. We therefore consider an offer of 40 slots per 100 children as representing full coverage.
} 
Table 9: Effects under alternative policy scenarios

\begin{tabular}{|c|c|c|c|c|}
\hline & zero to current & & current to full & \\
\hline \multicolumn{5}{|c|}{ A. Language Skills } \\
\hline Understands & -.329 & $(.205)$ & .374 & $(.339)$ \\
\hline ShortPhrase & .128 & $(.357)$ & .192 & $(.552)$ \\
\hline ShortMsg & -.050 & $(.424)$ & .390 & $(.584)$ \\
\hline LongPhrase & -.652 & $(.510)$ & -.439 & $(.773)$ \\
\hline ListenStory & .134 & $(.480)$ & -1.072 & $(.763)$ \\
\hline \multicolumn{5}{|l|}{ B. Social Skills } \\
\hline UsesNames & .083 & $(.103)$ & -.006 & $(.173)$ \\
\hline PlaysKids & -.078 & $(.389)$ & -.718 & $(.629)$ \\
\hline TalksEmotions & -.603 & $(.55)$ & .665 & $(.773)$ \\
\hline HasFriends & .059 & $(.520)$ & -.098 & $(.799)$ \\
\hline RolePlay & -.875 & $(.568)$ & .250 & $(.832)$ \\
\hline \multicolumn{5}{|l|}{ C. Daily Skills } \\
\hline EatsSpoon & -.150 & $(.615)$ & -.166 & $(.949)$ \\
\hline BrushesTeeth & -.441 & $(.599)$ & .490 & $(.893)$ \\
\hline CleansNose & -.170 & $(.526)$ & .920 & $(.969)$ \\
\hline ToiletNo2 & -.818 & $(.468)$ & -.874 & $(.800)$ \\
\hline DressesAlone & -.707 & $(.432)$ & .868 & $(.954)$ \\
\hline \multicolumn{5}{|l|}{ D. Motor Skills } \\
\hline OpensDoor & .190 & $(.211)$ & .246 & $(.289)$ \\
\hline WalksStairs & -.080 & $(.369)$ & .054 & $(.422)$ \\
\hline Climbs & .106 & $(.439)$ & .116 & $(.787)$ \\
\hline UsesScissors & -.11 & $(.507)$ & .085 & $(.827)$ \\
\hline Paints & -.468 & $(.487)$ & .313 & $(.818)$ \\
\hline
\end{tabular}

Notes: This Table displays how expanding the supply of child care slots from zero to its current level affects the children in care (column "zero to current"), and how expanding supply from its current level to 40 slots for 100 children would affect child development (column "current" to "full"). Estimates are based on equation 7 including a second order polynomial of the propensity score. Bootstrap (250 repetitions) standard errors are shown in parentheses.

Source: SOEP, Own Calculations 
currently attending child care. The simulation of a further expansion towards full coverage reveals, however, mostly beneficial effects: children are more likely to master 13 out of 20 skill dimensions. In other words, a further expansion of center-based child care seems to carry beneficial effects for children's early skill development. Unfortunately, our small sample prevents us again from making any statement based on significant results.

\subsection{Estimates}

Is there a way to aggregate the MTE in a sensible way? As outlined by Heckman and Vytlacil $(1999,2005)$ any parameter discussed in the literature can be constructed averaging across the MTE with the appropriate weights (for details, please refer to Appendix A.2). In the reminder of this paper we focus on one particular aggregate measure: linear IV estimates.

Linear IV estimates illustrate a highly policy relevant estimate - the effects for children who only select into child care once access barriers are lifted. This becomes clear when looking at Figure A.1 in the Appendix A.2 which displays the distribution of the IV weights along the entire range of the "unobserved component" of the propensity score. Substantial weight is attached to children with "unobserved entry barriers" between $u=0.1$ and $u=0.7$ and the maximum weight is attained for children with "unobserved entry barriers" of around $u=0.36$. Hence, linear IV estimates will therefore single out child care attendance effects for children rather less likely to attend child care in terms of their unobservable characteristics. Table 10 reports the effects of child care on children's skill development based on IV estimates.

The impact of center-based care attendance on the skills of children that only start attending center-based care once access constraints are lifted is mainly positive. Strongest gains from attending center-based child care are observed in terms of social skills. Once attending center-based care children are 5.8 percentage points more likely to play with other children, 6.8 percentage points more likely to refer to their emotions, 7.5 percentage points more likely to engage in role plays and finally 11.7 percentage points more likely to have friends. Turning to language skills, children are 7.6 percentage points more likely to listen attentively to a story of five minutes but 3.2 percentage points less likely to form short phrases. Motor skills improve: children are 10.1 percentage points more likely to know how to use scissors. Daily skills are not affected by exposure to center based care.

\subsection{Underlying Mechanisms}

What are channels underlying the effects of center-based care attendance? Table 11 displays how proxies of several key reasons why center-based care might affect children's skills are altered once children with high access barriers start attending care: different modes of care, mother-child interactions and mothers' participation in the labor market. 
Table 10: Child care and child development: IV estimates

\begin{tabular}{|c|c|c|c|c|c|}
\hline \multicolumn{6}{|c|}{ A. Language Skills } \\
\hline & Understands & ShortPhrase & ShortMsg & LongPhrase & ListenStory \\
\hline \multirow[t]{2}{*}{ In Child Care } & 0.002 & $-0.032^{*}$ & 0.037 & 0.037 & $0.076^{* *}$ \\
\hline & $(0.009)$ & $(0.019)$ & $(0.023)$ & $(0.031)$ & $(0.032)$ \\
\hline \multicolumn{6}{|l|}{ Chi2 } \\
\hline Children & 870 & 870 & 870 & 870 & 870 \\
\hline \multicolumn{6}{|c|}{ B. Social Skills } \\
\hline & UsesNames & PlaysKids & TalksEmotions & HasFriends & RolePlay \\
\hline \multirow[t]{2}{*}{ In Child Care } & -0.010 & $0.058^{* *}$ & $0.068^{* *}$ & $0.117^{* * *}$ & $0.075^{* *}$ \\
\hline & $(0.012)$ & $(0.023)$ & $(0.031)$ & $(0.032)$ & $(0.034)$ \\
\hline \multicolumn{6}{|l|}{ Chi2 } \\
\hline Children & 870 & 870 & 870 & 870 & 870 \\
\hline \multicolumn{6}{|c|}{ C. Daily Skills } \\
\hline & EatsSpoon & BrushesTeeth & CleansNose & ToiletNo2 & DressesAlone \\
\hline \multirow[t]{2}{*}{ In Child Care } & 0.019 & -0.057 & -0.022 & 0.043 & 0.044 \\
\hline & $(0.033)$ & $(0.041)$ & $(0.039)$ & $(0.035)$ & $(0.031)$ \\
\hline \multicolumn{6}{|l|}{ Chi2 } \\
\hline Children & 870 & 870 & 870 & 870 & 870 \\
\hline \multicolumn{6}{|c|}{ D. Motor Skills } \\
\hline \multirow{3}{*}{ In Child Care } & OpensDoor & WalksStairs & Climbs & UsesScissors & Paints \\
\hline & 0.013 & -0.002 & 0.049 & $0.101^{* * *}$ & -0.010 \\
\hline & $(0.015)$ & $(0.018)$ & $(0.031)$ & $(0.038)$ & $(0.035)$ \\
\hline \multicolumn{6}{|l|}{ Chi2 } \\
\hline Children & 870 & 870 & 870 & 870 & 870 \\
\hline
\end{tabular}

Notes: All estimates are based on 2SLS estimations using the local child care offer rate as instrument and controlling for the full set of individual and regional characteristics as well as a set of cohort and state dummies. Source: SOEP, Own Calculations 
Table 11: Underlying Mechanisms

\begin{tabular}{|c|c|c|c|c|}
\hline \multicolumn{5}{|c|}{ A. Child Care (hours per week) } \\
\hline & Center & Mother & Family & Informal \\
\hline \multirow{2}{*}{ Child Care } & $26.455^{* * *}$ & $-30.000^{* * *}$ & 5.787 & $-3.909^{*}$ \\
\hline & $(4.654)$ & $(10.559)$ & $(11.789)$ & $(2.246)$ \\
\hline Chi-Squared & 1169.167 & 132.800 & 87.054 & 84.291 \\
\hline \multirow[t]{3}{*}{ Children } & 870 & 860 & 845 & 867 \\
\hline & \multicolumn{4}{|c|}{ B. Quality of Care by Mother } \\
\hline & CognitiveAct & MotorAct & PassiveAct & \\
\hline \multirow[t]{2}{*}{ Child Care } & $0.344^{*}$ & 0.259 & $-0.368^{*}$ & \\
\hline & $(0.195)$ & $(0.211)$ & $(0.209)$ & \\
\hline Chi-Squared & 156.049 & 69.318 & 38.588 & \\
\hline \multirow[t]{3}{*}{ Children } & 870 & 870 & 870 & \\
\hline & \multicolumn{4}{|c|}{ C. Work and Income (Changes) } \\
\hline & dWork & dMomGrossInc & dHhNetInc & \\
\hline \multirow[t]{2}{*}{ Child Care } & $23.105^{* * *}$ & $1286.852^{* * *}$ & 434.268 & \\
\hline & $(6.995)$ & $(398.475)$ & $(676.523)$ & \\
\hline Chi-Squared & 48.020 & 48.194 & 49.964 & \\
\hline Children & 845 & 741 & 870 & \\
\hline
\end{tabular}

Notes: All estimates are based on 2SLS estimations using the local child care offer rate as instrument and controlling for the full set of individual and regional characteristics as well as a set of cohort and state dummies. dWork correpsonds to the change in actual weekly hours of work between survey when child is 3 years old and survey when child is two years old. dMomGrossInc is the equivalent change in nominal gross income (Euros per month).

Source: SOEP, Own calculations 
How many hours does the marginal child spend in center-based care and what type of care is crowded out by center-based care? Panel A of Table 11 displays the results regarding the time children spend in center-based care, in informal paid care (care provided by a child minder or a nanny), with the mother and with the extended family (the father, the grandparents, siblings or other relatives). Mothers of children with high entry barriers place their child during 26.5 hours per week in child care. Hence, their demand for child care is stronger than the demand of the average mother (18.6 hours per week). Once their children attend center-based care, their mothers dedicate on average 30.0 hours per week less to child care. In addition, children spend slightly less time in informal care (3.9 hours per week). Yet, there is no significant crowding out of family care. This suggests that children with high entry barriers tend to receive 26.5 hours of high quality care from the center in exchange of care provided mainly by their mother.

What happens to the quality of care provided by the mother? Once sending their children to child care, mothers reduce the time spent on activities that are not directly stimulating the development of their child such as running errands or watching TV. They increase, however, the frequency with which they undertake activities that stimulate children's cognitive skills, such as reading, singing, or painting. Note, however, none of these results refer to duration. Thus mothers might have undertaken stimulating activities more often but they may have reduced their duration. These results suggest that the quality of maternal care does not deteriorate as a result of sending their child to center-based care.

Does child care stimulate mothers' labor force participation? Panel C, Table 11 shows that mothers mainly use their additionally gained time to work. Once sending their child to child care, mothers work 23.1 hours per week more. As a result, their monthly gross income increases by 1287 Euros. The increase in mother's gross income is, however, not sufficient to cause a significant increase in the households' monthly net income. This is possibly due to the fact that one can deduct child care fees and costs of commuting from taxes.

Taken together, we can identify the following main channels underlying the improvements in children's skills. The first reason is substitution between time spent in a center-based care and time spent with the mother. Whether this crowding out has beneficial or detrimental effects on children's development depends on the relative quality of the care provided by the mother and the center-based care. Second, the reduction in mother's time devoted to their children does not lead to a reduction in the frequency of high-quality mother-child interactions. Third, the fact that center-based care allows mothers to join the labor market and thus to contribute to the household income, might have additional positive effects on children's development. 


\section{Conclusions}

The focus of our study lies on the causal effect of high-quality center-based child care during early childhood on children's short-run development in a wide range of skills. We are particularly interested in understanding the heterogeneity of these effects with respect to observed as well as unobserved determinants of the propensity to attend child care. A marginal treatment effects framework allows us to shed some light on these dimensions of heterogeneity.

The main findings of this paper are as follows. First, older children and children from advantageous backgrounds are the first to be sent to center-based care. Second, these children are the ones who benefit least from center-based care attendance. Gains are particularly high for younger children, boys, low birth weight children and children from low SES families. Third, heterogeneity in gains from child care with respect to unobserved determinants of the propensity to attend child care are not important, if anything returns seem to be increasing in unobserved determinants to attend child care. Finally, high-quality center-based child care is likely to exert its positive effects due to three reasons: a crowding out of maternal care, an increase in the quality of the remaining interactions between the mother and the child, and an increase in maternal work hours and thus maternal earnings.

These findings add to the current debate on how to support families in combining market work and family life. Our study indicates that there are no costs in terms of early child development of setting up a tightly regulated and high quality system of formal child care. Quite the opposite, our findings indicate that universally accessible care can even contribute to decrease inequalities across children from different socio-economic backgrounds. Currently, children that are likely to benefit the most from attending center-based care are not yet enrolled. Expanding high-quality center-based care to those children is likely to help them catch up with their peers and thus to level the playing field. 


\section{References}

Altonji, J., Elder, T., and Taber, C. (2005). Selection on observed and unobserved variables: Assessing the effectiveness of catholic schools. Journal of Political Economy, 113(1), 151-184.

Baker, M. and Milligan, K. (2012). Maternity leave and childrens cognitive and behavioral development. Nber working paper, NBER.

Baker, M., Gruber, J., and Milligan, K. (2008). Universal child care, maternal labor supply, and family well-being. Journal of Political Economy, 116(4), 709-745.

Baum, C. (2003). Does early maternal employment harm child development? an analysis of the potential benefits of leave taking. Journal of Labor Economics, 21(2).

Belsky, J. (2001). Developmental risks (still) associated with early child care. Journal of Child Psychology and Psychiatry, 42(October), 845859.

Belsky, J., Vandell, D., Burchinal, M., Clarke-Stewart, A., Mccartney, K., and Owen, M. (2007). Are there long-term effects of early child care? Child Development, 78(2), 681-701.

Berlinski, S., Galiani, S., and Gertler, P. (2009). The effect of pre-primary education on primary school performance. Journal of Public Economics, 93(1-2), 219-234.

Black, S. E., Devereux, P. J., Loken, K. V., and Salvanes, K. G. (2012). Care or cash? the effect of child care subsidies on student performance. IZA Discussion Papers 6541, Institute for the Study of Labor (IZA).

Blau, D. and Currie, J. (2006). Who is minding the kids. The Handbook of Education Economics.

Blau, F. and Grossberg, A. (1992). Maternal labor supply and children's cognitive development. Review of Economics and Statistics, 77, 231-249.

Brooks-Gunn, J., Han, W.-J., and Waldfogel, J. (2002). The effects of early maternal employment on child cognitive development. Demography, 39(2), 369-92.

Carneiro, P., Loken, K., and Salvanes, K. G. (2010). A flying start? long term consequences of time investments in infants in their first year of life. working paper, $\mathrm{NNH}$.

Carneiro, P., Heckman, J., and Vytlacil, E. (2011). Estimating marginal returns to education. American Economic Review, 101, 27542781.

Cascio, E. (2009). Do investments in universal early education pay off? long-term effects of introducing kindergartens into public schools. Working Paper 14951, NBER. 
Cunha, F., Heckman, J., Lochner, L., and Masterov, D. (2006). Interpreting the evidence on life cycle skills formation. In E. Hanushek, editor, Handbook of the Economis of Education, volume I, pages 310-451, Amsterdam. Elsevier.

Dahl, G. and Lochner, L. (2012). The impact of family income on child achievement: Evidence from changes in the earned income tax credit. American Economic Review, 102(5), 19271956.

Datta-Gupta, N. and Simonsen, M. (2010). Non-cognitive child outcomes and universal high quality child care. Journal of Public Economics, 94(1-2), 30-43.

Dittrich, G., Peucker, C., and Schneider, K. (2002). Zahlenspiegel: Daten zu tageseinrichtungen fr kinder. Technical report, Deutsches Jugendinstitut e.V.

Dustmann, C. and Schoenberg, U. (2012). The effect of expansions in maternity leave coverage on childrens long-term outcomes. American Economic Journal: Applied Economics.

Dustmann, C., Raute, A., and Schoenberg, U. (2012). Does universal child care matter? evidence from a large expansion in pre-school education. mimeo, UCL.

Felfe, C., Nollenberger, N., and Rodriguez-Planas, N. (2012). Can't buy mommy's love? universal child care and children's long-run cognitive development. Working paper, St. Gallen.

Fitzpatrick, M. D. (2008). Starting school at four: The effect of universal pre-kindergarten on children's academic achievement. The B.E. Journal of Economic Analysis \& Policy, 8(1), 46.

Gonzalez, L. (2012). The effects of a universal child benefit. American Economic Journal: Economic Policy.

Gormley Jr., W. T., Phillips, D., and Gayer, T. (2008). THE EARLY YEARS: Preschool Programs Can Boost School Readiness. Science, 320(5884), 1723-1724.

Havnes, T. and Mogstad, M. (2011). No child left behind: Universal child care and childrens long-run outcomes. American Economic Journal: Economic Policy, 3(2), 97-129.

Heckman, J. and Masterov, D. (2007). The productivity argument for investing in young children. Science, 29(3), 446-493.

Heckman, J. and Vytlacil, E. (1999). Local instrumental variables and latent variable models for identifying and bounding treatment effects. Proceedings of the National Academy of Sciences, 96(8), 4730-34.

Heckman, J. and Vytlacil, E. (2001). Policy relevant treatment effects. American Economic Review, 91(2), 107-11. 
Heckman, J. and Vytlacil, E. (2005). Structural equation, treatment effects, and econometric policy evaluation. Econometrica, 73(3), 669-738.

Heckman, J. and Vytlacil, E. (2007a). Econometric evaluation of social programs, part i: Causal models, structural models and econometric policy evaluations. In J. Heckman and E. Leamer, editors, Handbook of the Econometrics, volume 6B, pages 4779-4874, New York.

Heckman, J. and Vytlacil, E. (2007b). Econometric evaluation of social programs, part ii: Using the marginal treatment effect to organize alternative econometric estimators to evaluate social programs and to forecast their effects in new environments. In J. Heckman and E. Leamer, editors, Handbook of the Econometrics, volume 6B, pages 4875-5144, New York.

Heckman, J. and Vytlacil, E. J. (2000). Local instrumental variables. NBER Technical Working Papers 0252, National Bureau of Economic Research, Inc.

Huesken, K. (2010). Kita vor ort: Betreuungsatlas auf eben der jugendamtsbezirke 2010. Technical report, Deutsches Jugendinstitut e.V.

James-Burdumy, S. (2005). The effect of maternal labor force participation on child development. Journal of Labor Economics, 23(1), 177-211.

Magnuson, K. A., Ruhm, C. J., and Waldfogel, J. (2007). Does Prekindergarten Improve School Preparation and Performance? Economics of Education Review, 26, 33-51.

Manski, C. F. (1993). Identification of Endogenous Social Interactions: The Reflection Problem. Review of Economic Studies, 60(3), 531-542.

Noboa Hidalgo, G. and Urzúa, S. (2010). The effect of participation in public childcare centers: Evidence from chile. Working paper, Northwestern University.

Riedel, B., Gadow, T., van Santen, E., Fuchs, K., Schilling, M., and Leu, H. R. (2005). Zahlenspiegel: Kindertagesbetreuung im spiegel der statistik. Technical report, Deutsches Jugendinstitut e.V. und Dortmunder Arbeitsstelle Kinder- und Jugendhilfestatistik.

Ruhm, C. (2004). Parental employment and child cognitive development. Journal of Human Resources, 39(1), 155-192.

Schatz, J. and Hamdan-Allen, G. (1995). Effects of age and iq on adaptive behavior domains for children with autism. Journal of Autism and Developmental Disorders, 25(1), 51-60.

Sparrow, S. S. and Cicchetti, D. V. (1985). Diagnostic uses of the vineland adaptive behavior scales. Journal of Pediatric Psychology, 10(2), 215-225. 
Szatmari, P., Bryson, S. E., Boyle, M. H., Streiner, D., and Duku, E. (2003). Predictors of outcome among high functioning children with autism and asperger syndrome. Journal of Child Psycholy and Psychiatry, 44(4), 520-8.

Voelker, S., Shore, D., Hakim-Larson, J., , and Bruner, D. (1997). Discrepancies in parent and teacher ratings of adaptive behavior of children with multiple disabilities. Mental Retardation, 35(1), 10-17.

Vytlacil, E. (2002). Independence, monotonicity, and latent index models: An equivalence result. Econometrica, 70(1), 331-341.

Wagner, G., Frick, J., and Schupp, J. (2007). The german socio-economic panel study (soep) scope, evolution and enhancements. Schmollers Jahrbuch, 127, 139-169.

Wuertz-Rasmussen, A. (2010). Increasing the length of parents' birth-related leave : The effect on children's long-term educational outcomes. Labour Economics, 17(1), 91-100. 


\section{A Appendix: Using MTE to Recover Treatment Parameters}

\section{A.1 Policy Relevant Treatment Effects}

Following Heckman and Vytlacil (2001, 2005, 2007b) we consider different policies that change the probability to participate in child care, but that do not affect potential outcomes directly. In particular, we assess the effects of i) expanding the amount of available child care slots from zero to its current level and ii) expanding the amount of child care slots from its current level to a level where demand is fully satisfied (which is assumed to be at 40 slots per 100 children).

Setting the supply of child care to $z^{\prime}$ slots per 100 children changes the probability of attending child care, i.e. $p^{\prime}=\operatorname{Prob}\left(D=1 \mid X=x, Z=z^{\prime}\right) \neq p=\operatorname{Prob}(D=1 \mid X=x, Z=z)$ where $z$ refers to the slots per birth observed in the data and $z^{\prime}$ corresponds either to zero slots (under policy i) or to 40 slots per hundred children (under policy ii).

One can then predict the expected value of outcome $s$ after policy implementation $\left(y^{\prime}=\right.$ $\left.E\left(Y^{s} \mid X=x, P(W)=p^{\prime}\right)\right)$ and contrast it to the counterfactual outcome $\left(y=E\left(Y^{s} \mid X=\right.\right.$ $x, P(W)=p)$ ) in the absence of the policy. Heckman and Vytlacil $(2005,2007 \mathrm{a})$ show that the treatment impact of the policy for children with characteristics $X$ and propensity score $p$ corresponds to the policy relevant treatment effect and can be expressed as follows:

$$
\frac{E\left(Y^{s} \mid X=x, P(Z)=p^{\prime}\right)-E\left(Y^{s} \mid X=x, P(Z)=p\right)}{E\left(D \mid X=x, P(Z)=p^{\prime}\right)-E(D \mid X=x, P(Z)=p)}
$$

\section{A.2 Linear Instrumental Variable Estimates}

As established by Heckman and Vytlacil (1999, 2000, 2005, 2007a,b), any parameter can be constructed by aggregating MTE and using the appropriate weights. The general formula is

$$
\operatorname{PAR}(x)=\int_{0}^{1} \operatorname{MTE}(x, u) h_{P A R}(x, u) d u
$$

Using the propensity score as an instrument for child care attendance, the linear instrumental variable estimator aggregates MTE using the following weights

$$
h_{I V}=\left[\int_{u}^{1}(p-E(P \mid X=x)) f(p \mid X=x) d p\right] \frac{1}{\operatorname{Var}(P \mid X=x)}
$$

Thus, the linear IV estimate contrasts observations above and below the mean propensity score and weights observations with respect to the inverse of the variance of $P$. The weights will be 0 at 0 or 1 and give larger weight to observations in the middle. The linear IV weights therefore put a lot of weight on children with high values of $u$. Figure A.1 displays the distribution of the IV weights for our first stage (the propensity to attend child care using local supply as the instrument) along the entire range of the "unobserved component" of the propensity score. 
Figure A.1: Linear IV weights

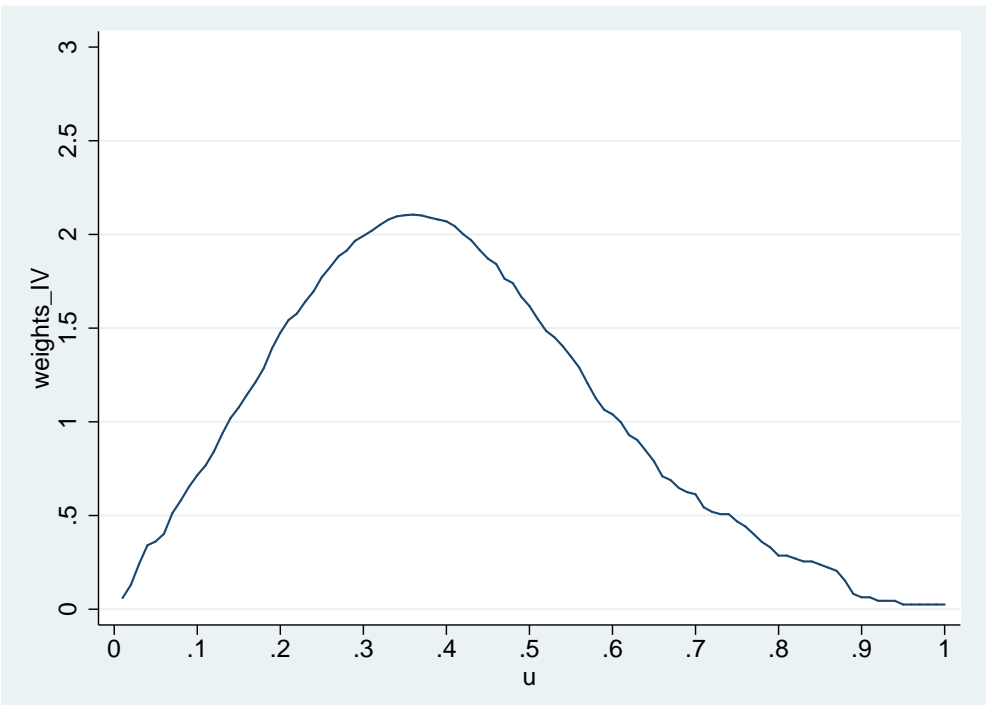

Notes: This graph reports the weights implicit in linear IV, h_IV (see equation 12). Source: SOEP, Own calculations

\section{B Appendix: Detailed Results of the MTE}


Table B.1: Child care and child development: Language skills

\begin{tabular}{|c|c|c|c|c|c|}
\hline & Understands & ShortPhrase & ShortMsg & LongPhrase & ListenStory \\
\hline \multirow[t]{2}{*}{ pZ $x$ age child } & $-0.534^{*}$ & -0.510 & -0.426 & -0.768 & 0.471 \\
\hline & $(0.291)$ & $(0.403)$ & $(0.376)$ & $(0.510)$ & $(0.622)$ \\
\hline \multirow[t]{2}{*}{ pZ x lowBirthWeight } & 0.255 & 0.142 & $0.492^{*}$ & $0.406^{*}$ & 0.071 \\
\hline & $(0.164)$ & $(0.242)$ & $(0.268)$ & $(0.238)$ & $(0.341)$ \\
\hline \multirow[t]{2}{*}{ pZ x Boy } & 0.048 & 0.136 & $0.293^{* *}$ & $0.263^{*}$ & 0.072 \\
\hline & $(0.072)$ & $(0.108)$ & $(0.113)$ & $(0.148)$ & $(0.170)$ \\
\hline \multirow[t]{2}{*}{ pZ $x$ age mother } & 0.001 & $-0.022^{*}$ & $-0.024^{*}$ & $-0.040^{* *}$ & 0.000 \\
\hline & $(0.007)$ & $(0.013)$ & $(0.013)$ & $(0.016)$ & $(0.022)$ \\
\hline \multirow[t]{2}{*}{$\mathrm{pZ} \times$ married } & $0.123^{*}$ & 0.070 & 0.151 & 0.058 & -0.274 \\
\hline & $(0.066)$ & $(0.152)$ & $(0.125)$ & $(0.195)$ & $(0.217)$ \\
\hline \multirow[t]{2}{*}{ pZ x nrkids } & 0.030 & 0.023 & -0.042 & 0.016 & 0.011 \\
\hline & $(0.034)$ & $(0.049)$ & $(0.085)$ & $(0.096)$ & $(0.095)$ \\
\hline \multirow[t]{2}{*}{ pZ $x$ high Educ } & $-0.272^{* *}$ & -0.203 & 0.012 & 0.021 & 0.394 \\
\hline & $(0.127)$ & $(0.196)$ & $(0.194)$ & $(0.291)$ & $(0.332)$ \\
\hline \multirow[t]{2}{*}{$\mathrm{pZ} \times$ high Inc } & -0.095 & -0.036 & -0.251 & -0.024 & 0.480 \\
\hline & $(0.098)$ & $(0.156)$ & $(0.210)$ & $(0.308)$ & $(0.365)$ \\
\hline Het unobs. & 0.109 & 0.912 & 0.449 & 0.810 & 0.216 \\
\hline Het. Individual & 0.543 & 0.000 & 0.000 & 0.076 & 0.721 \\
\hline Het. Regional & 0.026 & 0.175 & 0.038 & 0.292 & 0.112 \\
\hline Het. States & 0.109 & 0.273 & 0.420 & 0.004 & 0.032 \\
\hline R-squared & 0.065 & 0.114 & 0.080 & 0.106 & 0.034 \\
\hline Children & 870 & 870 & 870 & 870 & 870 \\
\hline
\end{tabular}

Notes: Estimates of this table stem from a reduced form estimation of language skills projected on the propensity score (second order polynomial) and its interactions with individual and regional characteristics, state and cohort dummies. Each line displays the parameter belonging to the interaction between the propensity score and the respective feature. These parameters allow us to assess for whom child care attendance exhibits greater effects. At the bottom p-values of four statistical tests are displayed: i) heterogeneity with respect to unobserved characteristics, ii) a test for heterogeneity with respect to individual characteristics ("Het. Individual"), iii) a test for heterogeneity with respect to regional characteristics ("Het. Regional"), and iv) a test for heterogeneity across states ("Het. States").

Source: SOEP, Own Calculations. 
Table B.2: Child Care and Child Development: Social Skills

\begin{tabular}{lccccc}
\hline \hline & UsesNames & PlaysKids & TalksEmotions & HasFriends & RolePlay \\
\hline pZ x age child & 0.090 & 0.281 & $-1.301^{* *}$ & -0.267 & $-1.436^{* *}$ \\
& $(0.139)$ & $(0.473)$ & $(0.573)$ & $(0.681)$ & $(0.651)$ \\
pZ x lowBirthWeight & -0.100 & -0.019 & 0.233 & 0.118 & $0.668^{* *}$ \\
& $(0.112)$ & $(0.258)$ & $(0.278)$ & $(0.302)$ & $(0.318)$ \\
pZ x Boy & 0.048 & -0.066 & $0.300^{*}$ & -0.069 & -0.054 \\
& $(0.052)$ & $(0.106)$ & $(0.155)$ & $(0.148)$ & $(0.172)$ \\
pZ x age mother & $-0.014^{* *}$ & 0.004 & -0.017 & 0.001 & $-0.035^{*}$ \\
& $(0.006)$ & $(0.014)$ & $(0.015)$ & $(0.021)$ & $(0.020)$ \\
pZ x married & 0.070 & -0.148 & 0.114 & 0.254 & 0.077 \\
& $(0.047)$ & $(0.130)$ & $(0.186)$ & $(0.204)$ & $(0.180)$ \\
pZ x nrkids & 0.003 & -0.100 & $0.154^{*}$ & -0.109 & $0.189^{*}$ \\
& $(0.022)$ & $(0.067)$ & $(0.080)$ & $(0.085)$ & $(0.099)$ \\
pZ x high Educ & 0.078 & 0.504 & 0.180 & 0.284 & -0.354 \\
& $(0.090)$ & $(0.336)$ & $(0.300)$ & $(0.327)$ & $(0.280)$ \\
pZ x high Inc & 0.041 & -0.123 & -0.110 & 0.121 & 0.207 \\
& $(0.053)$ & $(0.167)$ & $(0.251)$ & $(0.237)$ & $(0.226)$ \\
\hline Het unobs. & 0.647 & 0.424 & 0.169 & 0.890 & 0.240 \\
Het. Individual & 0.219 & 0.179 & 0.000 & 0.419 & 0.035 \\
Het. Regional & 0.614 & 0.130 & 0.223 & 0.599 & 0.564 \\
Het. States & 0.000 & 0.005 & 0.000 & 0.000 & 0.451 \\
Children & 0.025 & 0.015 & 0.037 & 0.006 & 0.070 \\
\hline \hline
\end{tabular}

Notes: Estimates of this table stem from a reduced form estimation of language skills projected on the propensity score (second order polynomial) and its interactions with individual and regional characteristics, state and cohort dummies. Each line displays the parameter belonging to the interaction between the propensity score and the respective feature. These parameters allow us to assess for whom child care attendance exhibits greater effects. At the bottom p-values of four statistical tests are displayed: i) heterogeneity with respect to unobserved characteristics, ii) a test for heterogeneity with respect to individual characteristics ("Het. Individual"), iii) a test for heterogeneity with respect to regional characteristics ("Het. Regional"), and iv) a test for heterogeneity across states ("Het. States").

Source: SOEP, Own Calculations. 
Table B.3: Child Care and Child Development: Daily Skills

\begin{tabular}{|c|c|c|c|c|c|}
\hline & EatsSpoon & BrushesTeeth & CleansNose & ToiletNo2 & DressesAlone \\
\hline \multirow[t]{2}{*}{ pZ $x$ age child } & 0.025 & -0.871 & -0.604 & -0.075 & -0.722 \\
\hline & $(0.867)$ & $(0.726)$ & $(0.669)$ & $(0.579)$ & $(0.607)$ \\
\hline \multirow{2}{*}{ pZ x lowBirthWeight } & 0.280 & 0.145 & 0.515 & -0.174 & 0.220 \\
\hline & $(0.291)$ & $(0.370)$ & $(0.332)$ & $(0.356)$ & $(0.336)$ \\
\hline \multirow{2}{*}{ pZ x Boy } & 0.058 & 0.150 & -0.133 & -0.258 & 0.056 \\
\hline & $(0.192)$ & $(0.172)$ & $(0.169)$ & $(0.172)$ & $(0.170)$ \\
\hline \multirow[t]{2}{*}{$\mathrm{pZ} x$ age mother } & -0.010 & -0.026 & -0.012 & 0.016 & 0.001 \\
\hline & $(0.020)$ & $(0.024)$ & $(0.021)$ & $(0.020)$ & $(0.017)$ \\
\hline \multirow[t]{2}{*}{ pZ x married } & 0.195 & -0.186 & -0.140 & 0.068 & -0.224 \\
\hline & $(0.252)$ & $(0.211)$ & $(0.200)$ & $(0.167)$ & $(0.180)$ \\
\hline \multirow[t]{2}{*}{ pZ x nrkids } & 0.024 & 0.079 & $0.170^{*}$ & -0.045 & $0.147^{*}$ \\
\hline & $(0.095)$ & $(0.118)$ & $(0.088)$ & $(0.092)$ & $(0.081)$ \\
\hline \multirow[t]{2}{*}{ pZ x high Educ } & 0.022 & 0.097 & -0.275 & -0.005 & $-0.705^{* * *}$ \\
\hline & $(0.387)$ & $(0.355)$ & $(0.294)$ & $(0.275)$ & $(0.240)$ \\
\hline \multirow[t]{2}{*}{ pZ $x$ high Inc } & -0.032 & -0.070 & -0.354 & -0.110 & $-0.322^{*}$ \\
\hline & $(0.211)$ & $(0.232)$ & $(0.225)$ & $(0.193)$ & $(0.185)$ \\
\hline Het unobs. & 0.989 & 0.436 & 0.276 & 0.949 & 0.080 \\
\hline Het. Individual & 0.903 & 0.110 & 0.061 & 0.678 & 0.000 \\
\hline Het. Regional & 0.247 & 0.293 & 0.509 & 0.012 & 0.044 \\
\hline Het. States & 0.284 & 0.615 & 0.412 & 0.196 & 0.002 \\
\hline R-squared & 0.001 & 0.038 & 0.064 & 0.174 & 0.146 \\
\hline Children & 870 & 870 & 870 & 870 & 870 \\
\hline
\end{tabular}

Notes: Estimates of this table stem from a reduced form estimation of language skills projected on the propensity score (second order polynomial) and its interactions with individual and regional characteristics, state and cohort dummies. Each line displays the parameter belonging to the interaction between the propensity score and the respective feature. These parameters allow us to assess for whom child care attendance exhibits greater effects. At the bottom p-values of four statistical tests are displayed: i) heterogeneity with respect to unobserved characteristics, ii) a test for heterogeneity with respect to individual characteristics ("Het. Individual"), iii) a test for heterogeneity with respect to regional characteristics ("Het. Regional"), and iv) a test for heterogeneity across states ("Het. States").

Source: SOEP, Own Calculations. 
Table B.4: Child Care and Child Development: Motor Skills

\begin{tabular}{lccccc}
\hline \hline & OpensDoor & WalksStairs & Climbs & UsesScissors & Paints \\
\hline pZ x age child & 0.017 & -0.177 & 0.180 & -0.499 & -0.216 \\
& $(0.250)$ & $(0.426)$ & $(0.545)$ & $(0.602)$ & $(0.532)$ \\
pZ x lowBirthWeight & 0.329 & -0.068 & 0.459 & -0.296 & 0.048 \\
& $(0.222)$ & $(0.318)$ & $(0.282)$ & $(0.310)$ & $(0.298)$ \\
pZ x Boy & -0.073 & 0.121 & -0.122 & -0.238 & -0.265 \\
& $(0.054)$ & $(0.139)$ & $(0.167)$ & $(0.167)$ & $(0.163)$ \\
pZ x age mother & -0.008 & -0.007 & -0.006 & -0.001 & 0.003 \\
& $(0.008)$ & $(0.010)$ & $(0.016)$ & $(0.019)$ & $(0.016)$ \\
pZ x married & 0.093 & $0.228^{*}$ & 0.088 & -0.102 & -0.100 \\
& $(0.076)$ & $(0.117)$ & $(0.197)$ & $(0.191)$ & $(0.189)$ \\
pZ x nrkids & -0.006 & 0.056 & 0.055 & 0.048 & 0.048 \\
& $(0.031)$ & $(0.058)$ & $(0.092)$ & $(0.100)$ & $(0.093)$ \\
pZ x high Educ & 0.172 & -0.039 & 0.087 & 0.090 & 0.143 \\
pZ x high Inc & $(0.137)$ & $(0.206)$ & $(0.223)$ & $(0.278)$ & $(0.276)$ \\
& 0.033 & 0.043 & 0.134 & -0.050 & -0.136 \\
Het unobs. & $(0.092)$ & $(0.145)$ & $(0.226)$ & $(0.228)$ & $(0.214)$ \\
Het. Individual & 0.895 & 0.845 & 0.990 & 0.830 & 0.336 \\
Het. Regional & 0.160 & 0.002 & 0.268 & 0.040 & 0.002 \\
Het. States & 0.091 & 0.236 & 0.389 & 0.556 & 0.338 \\
\hline \hline & 0.420 & 0.009 & 0.591 & 0.665 & 0.274 \\
& 0.065 & 0.028 & 0.007 & 0.090 & 0.087 \\
& 870 & 870 & 870 & 870 & 870 \\
\hline
\end{tabular}

Notes: Estimates of this table stem from a reduced form estimation of language skills projected on the propensity score (second order polynomial) and its interactions with individual and regional characteristics, state and cohort dummies. Each line displays the parameter belonging to the interaction between the propensity score and the respective feature. These parameters allow us to assess for whom child care attendance exhibits greater effects. At the bottom p-values of four statistical tests are displayed: i) heterogeneity with respect to unobserved characteristics, ii) a test for heterogeneity with respect to individual characteristics ("Het. Individual"), iii) a test for heterogeneity with respect to regional characteristics ("Het. Regional"), and iv) a test for heterogeneity across states ("Het. States").

Source: SOEP, Own Calculations. 
Figure B.1: Conditional marginal treatment effects (high X score vs. low X score)
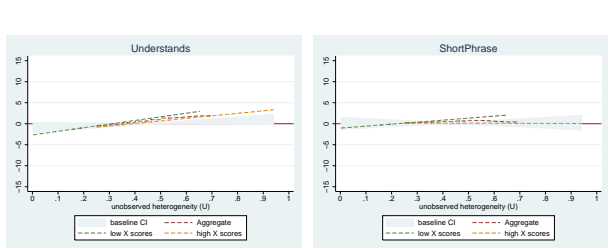

A. Language Skills
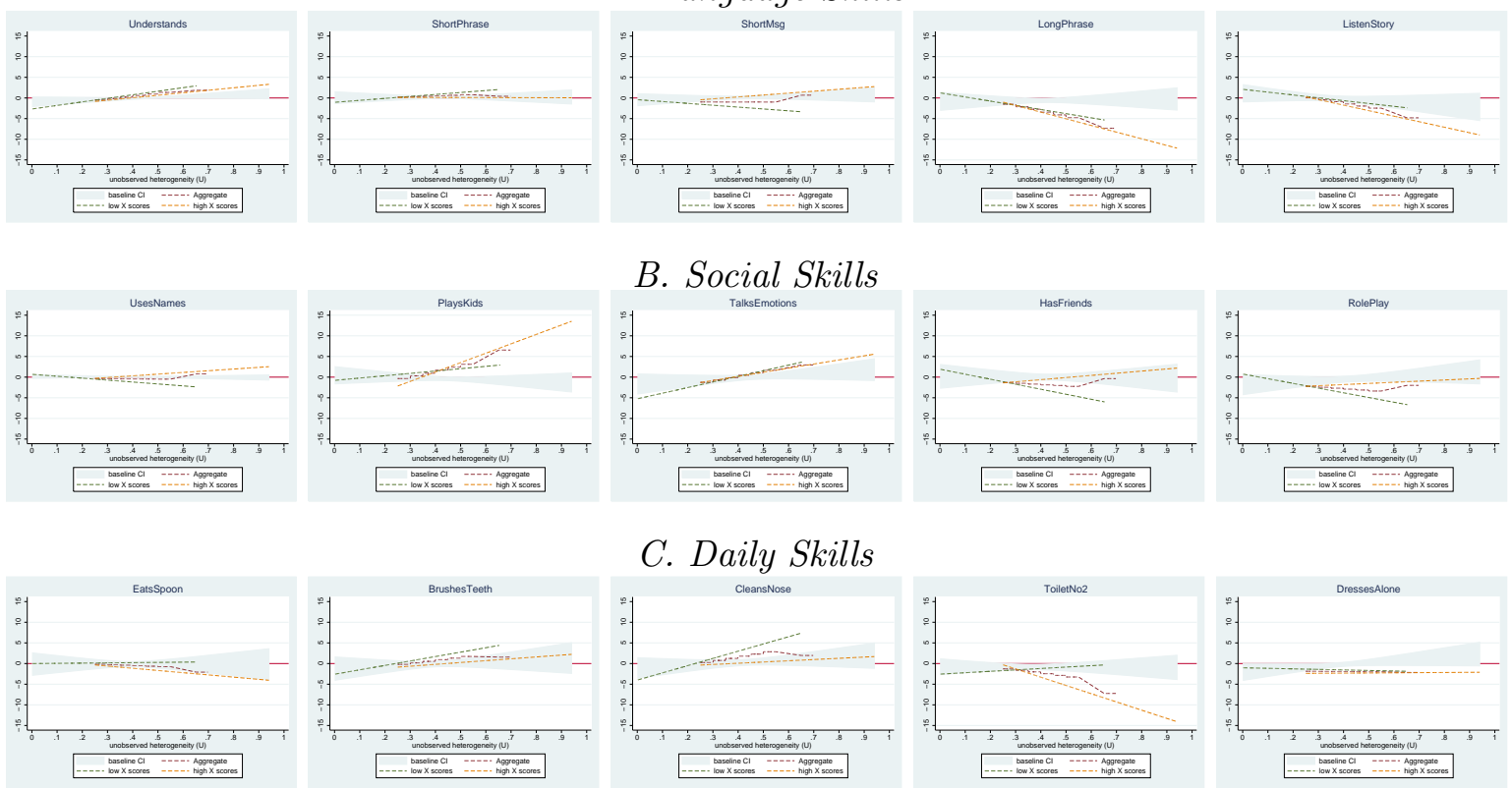

\section{Daily Skills}
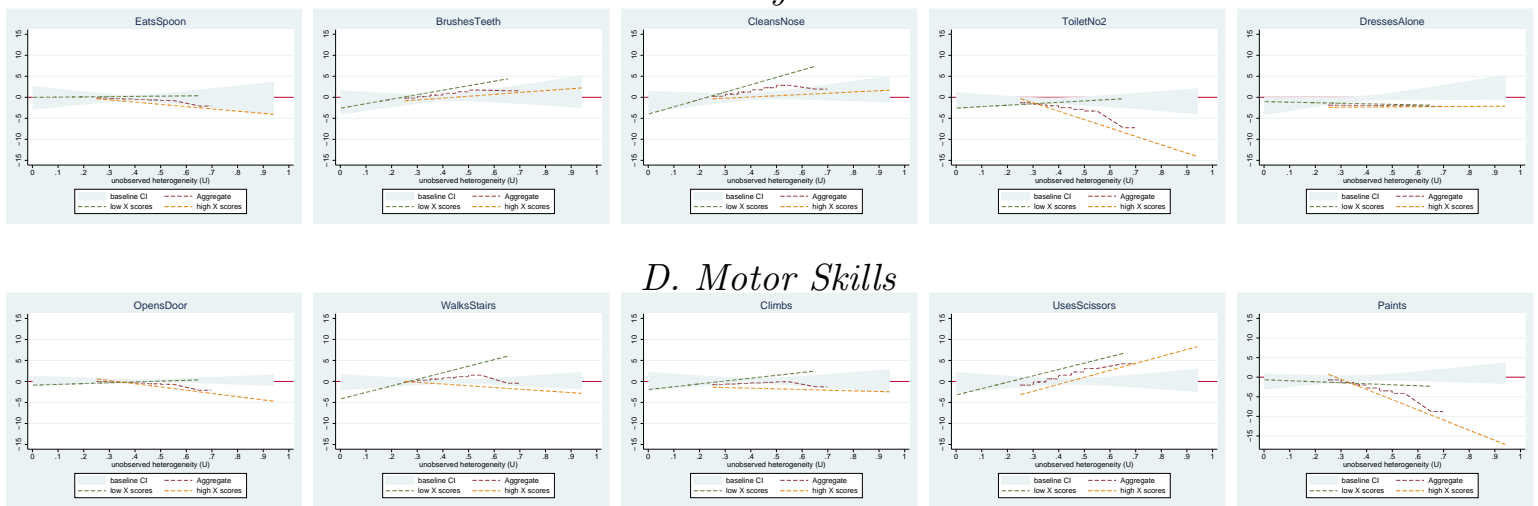

Notes: This Figure shows the effect of center-based care on the children who are indifferent between attending child care and not doing it. The Figure displays the component of the MTE that is related to unobserved characteristics $U_{D}$. We evaluate the MTE separately for children with a predicted propensity score above the median ("high X score") and below the median ("low X score"). Additionally we aggregate the estimates for both groups ("Aggregate"). All estimates are based on a polynomial approximation to the unobserved component using a $2^{\text {nd }}$ order polynomial, the area shades the $95 \%$ confidence interval of the baseline estimation. Source: SOEP, Own Calculations. 